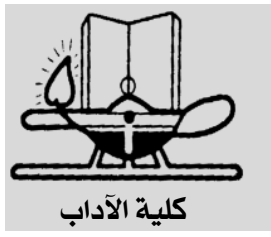

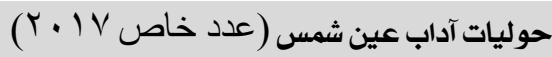
http://www.aafu.journals.ekb.eg

(دورية علمية محكمة)

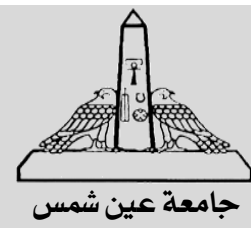

\title{
الأوضاع السياسية والدينية في إيران قبيل قيام الدولة الصفوية
}

عمرو السيا علي السيد

معيد بكلية الآداب جامعة عين شمس - قسم اللغات الثرقية وآدابها

قبل قيام الدولة الصفوية في إيران تهيأت لها ظروف وأوضاع سياسية واجتماعية،

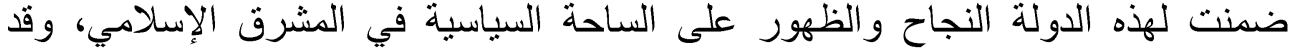
تأسست هذه الدولة على أساس ديني حيث اتخذت من المذهب الثيعي الاثتي عشري مذهبا

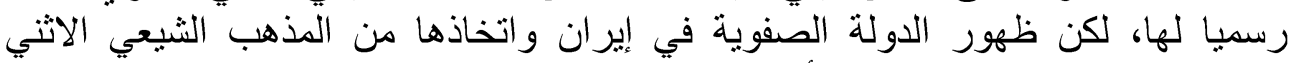

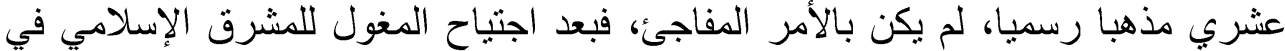

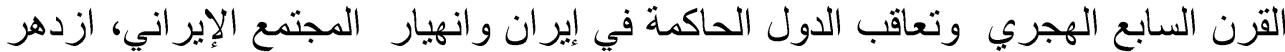

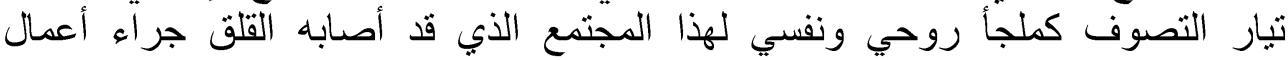

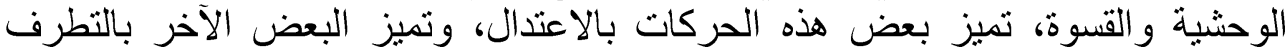

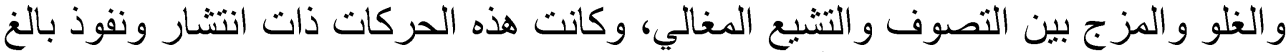
خاصة في المناطق الإيرانية والأناضول، كان لغياب المؤسسات الدينية الرسمية دور كبير

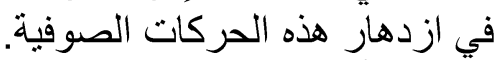

بدأت بعض هذه الحركات الصوفية المتنيعة تتخذ بعدا سياسيا ولم تكتفي بالزها هد المدات فقط، وقامت بعض هذه الحركات بثورات على الحكام المحليين كحركة السربداريين في بـاتي خراسان، بل واسنطاعت أيضا تأسيس دول لها، وغير الته حركة السربداريين، كانت هناك الك

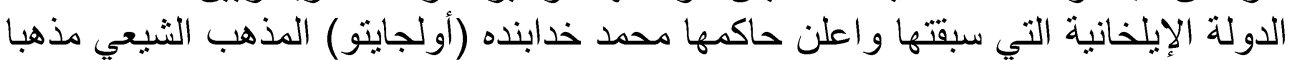

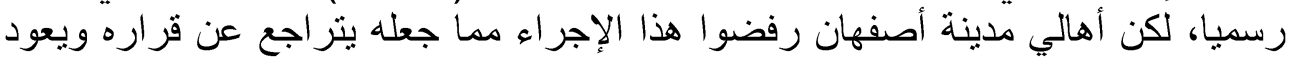

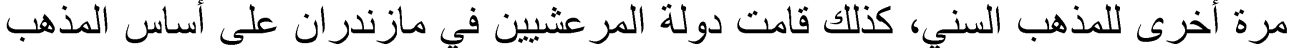
الثيعي الاثني عشري، ودولة المشعشعيين في خوزستان.

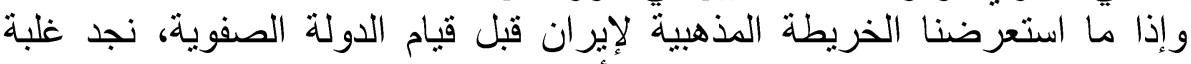

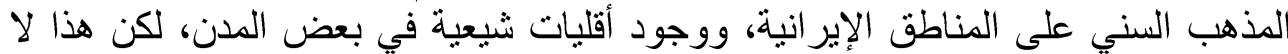

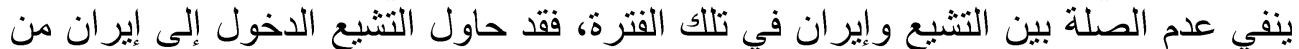
خلال طرق عديدة كان أهمها "التصوفة التصن". 
بدور هذا البحث حول أوضاع إيران السياسية و الدينية والاجتماعية قبل قيام الدولة المــقدمــة:

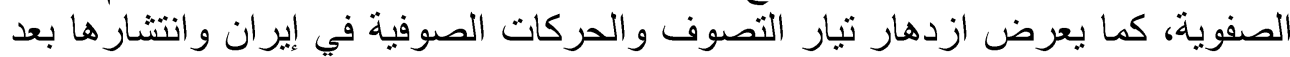

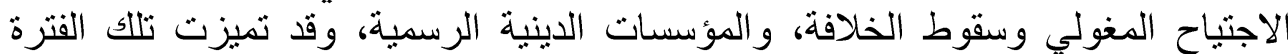

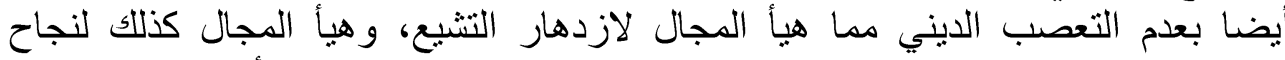

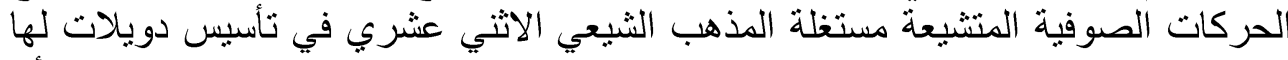

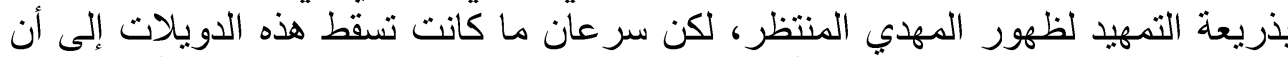

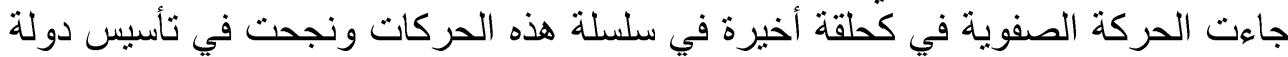

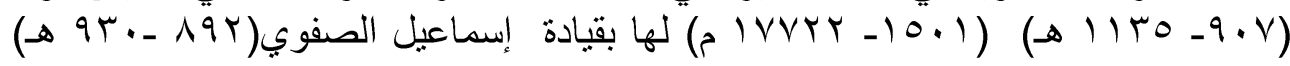
(lor $\varepsilon-1 \leqslant \Lambda V)$

اعتمد الباحث في هذا البحث على المصادر والمراجع العربية والفارسية ذات الصلة بالموضوع وقد اتبع الباحث في هذ البحث البحث المنهج التاريخي. الوضع السياسيى

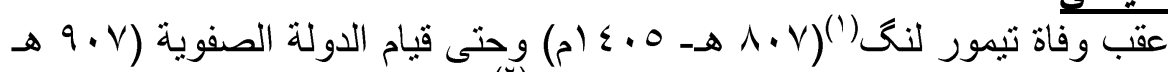

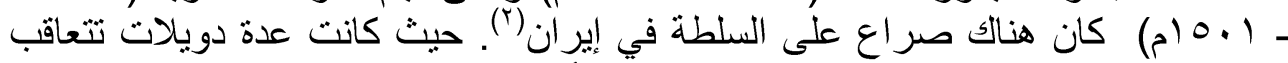

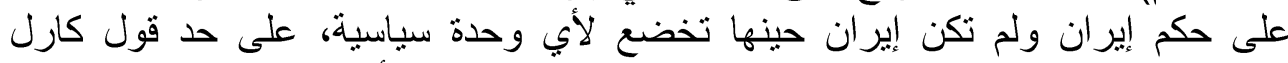

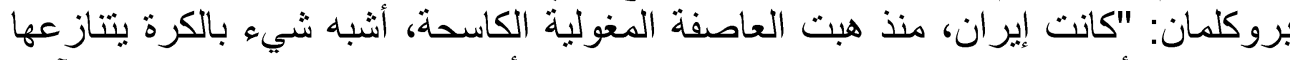

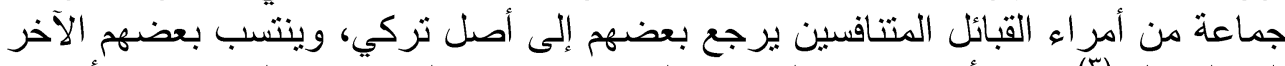

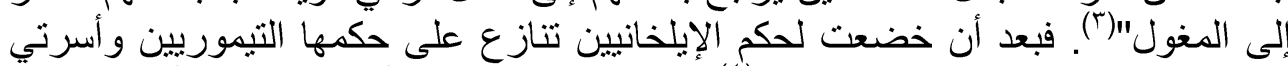

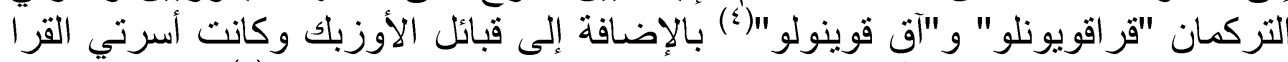

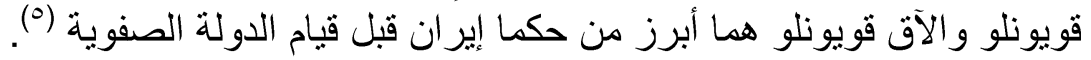

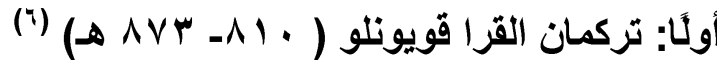

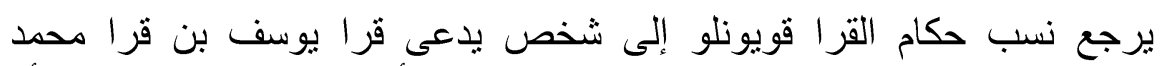

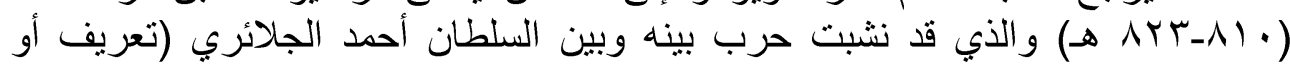

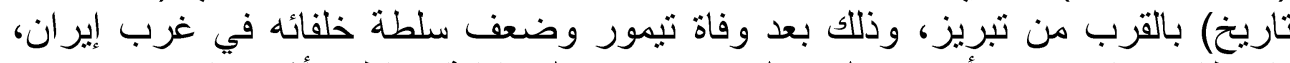

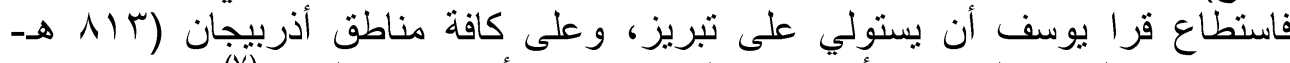

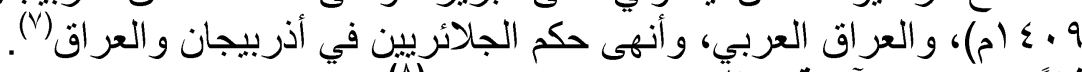

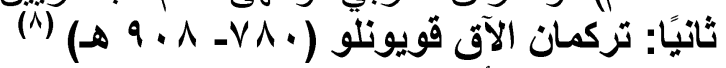

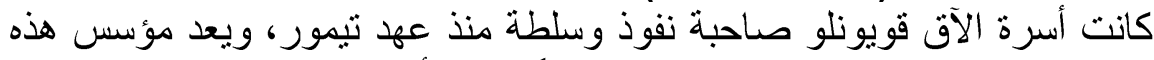

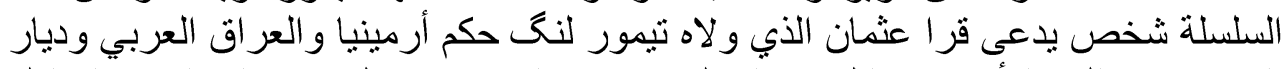

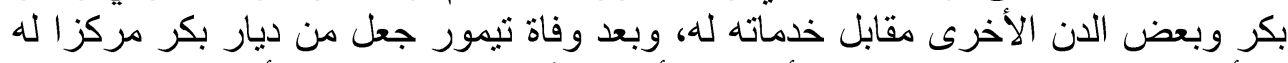

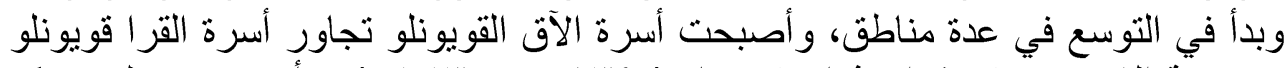

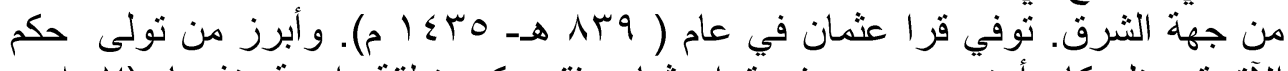

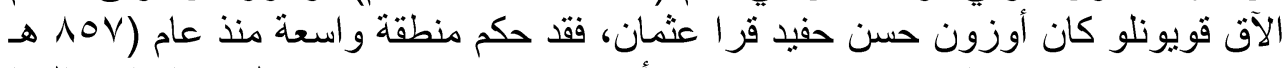

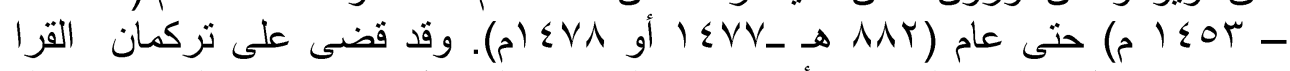

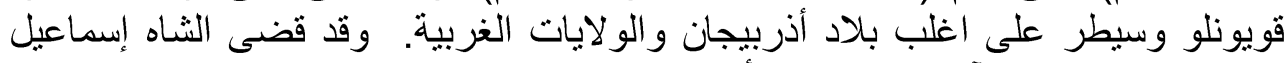

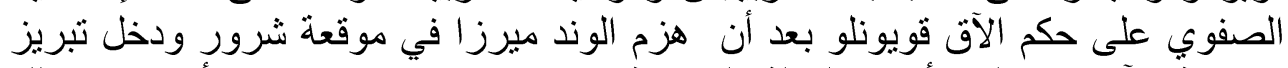

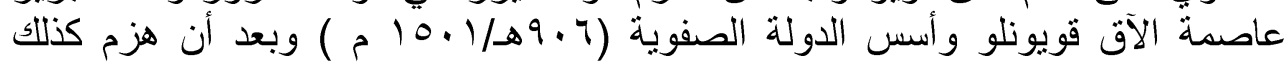


السلطان يعقوب ( م مجؤهـ) آخر حكام هذه الدولة الذي كن يحكم فارس والعراق

بالنسبة للوضع الديني في إيران قبل قيام الدولة الصفوية، كانت أغلبية سكان

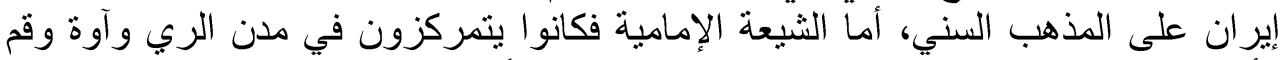

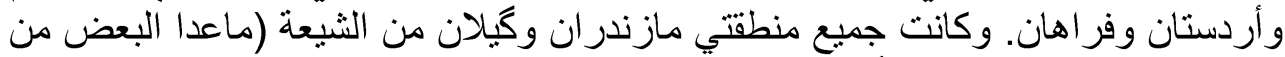

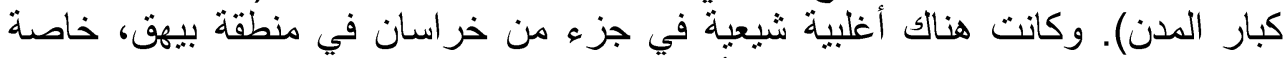

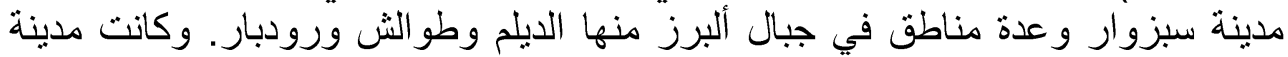

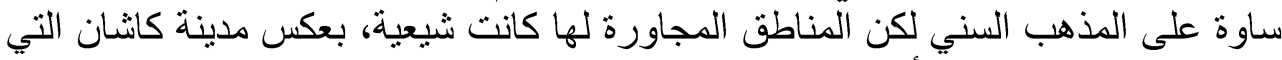

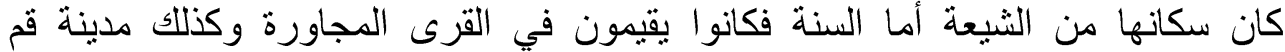

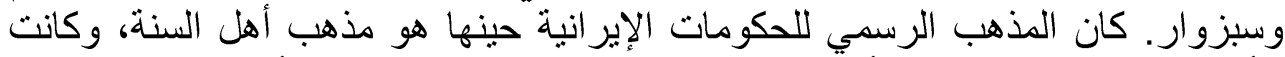

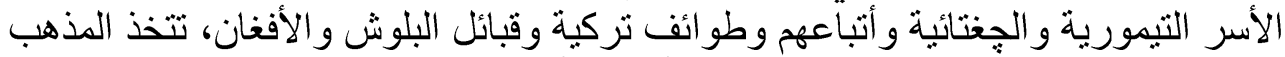

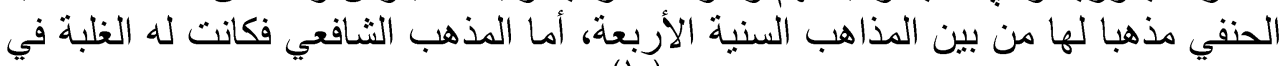

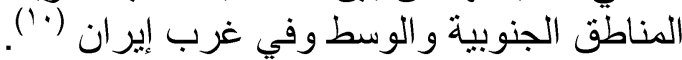

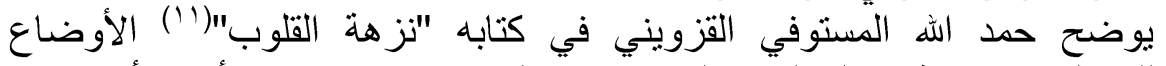

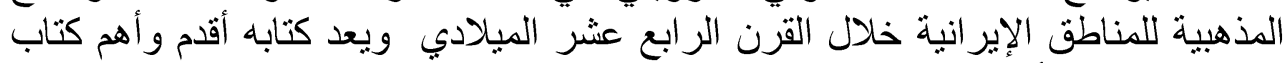

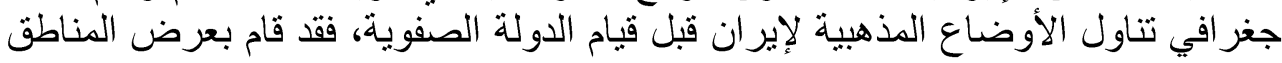

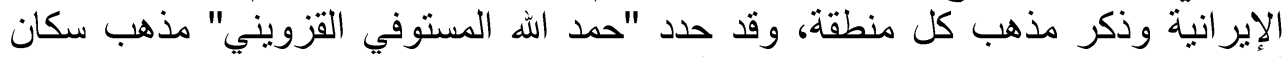

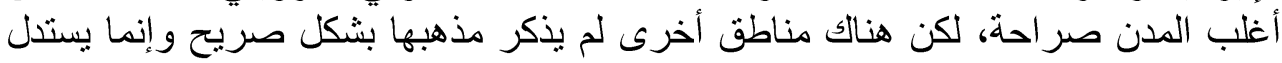

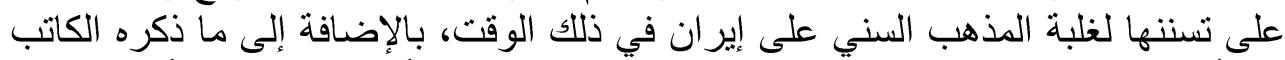

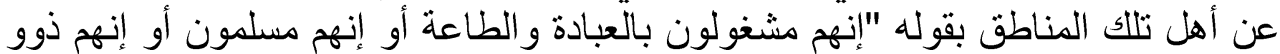

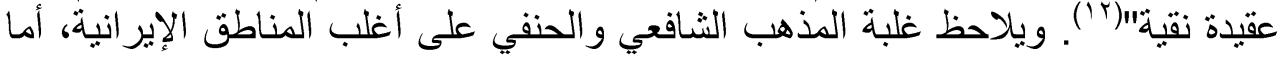

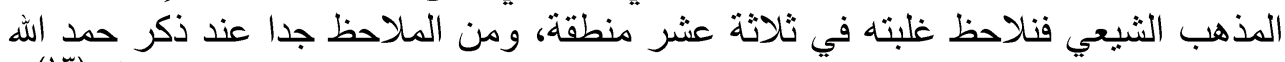

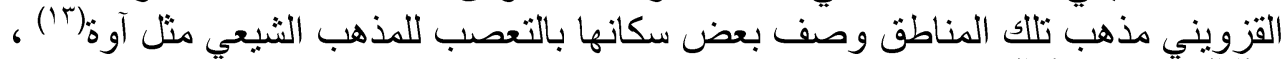

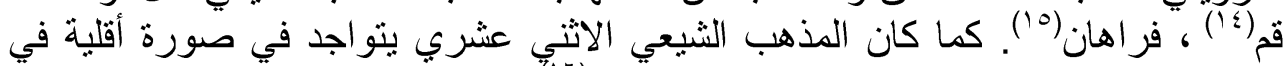

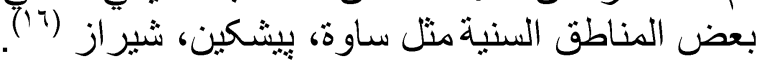

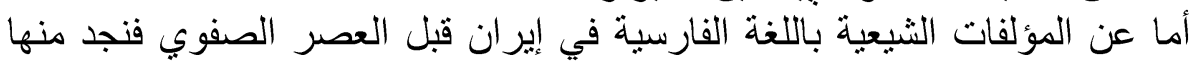

$$
\text { في القرن الثامن الهجري ما يلي: }
$$

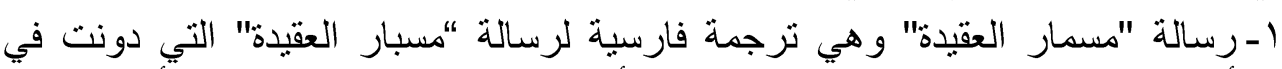

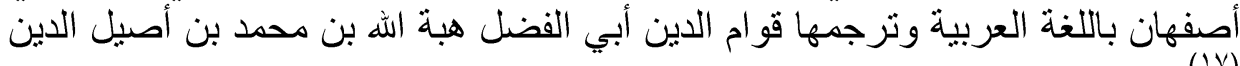

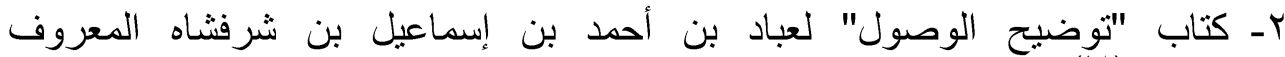

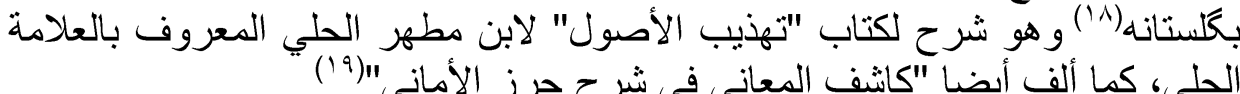

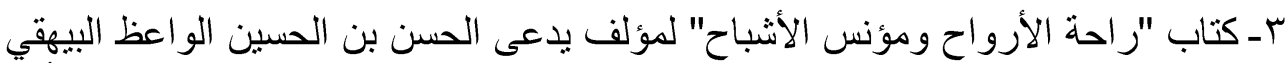

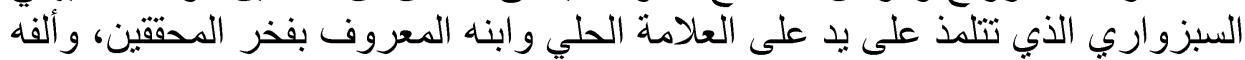

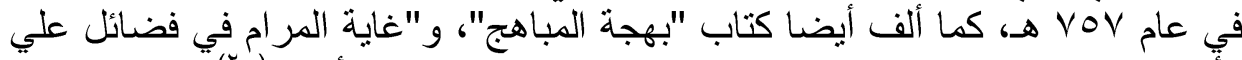

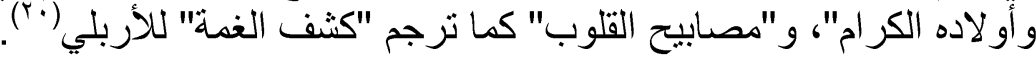

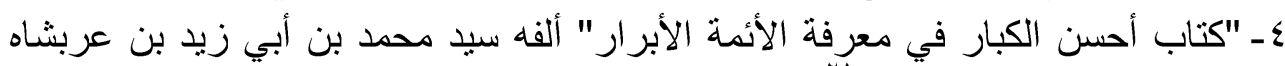

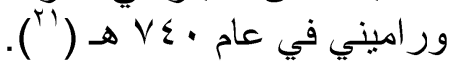


هـ "أمثلة التوحيد وجامع الحقائق" للفيلسوف الثيعي الإيراني حبدر الآملي (توفي بعد . $^{(r)}(\vee \wedge V$

7ـ كتاب "نفايس الفنون" ألفه محمد بن محمود الآملي أحد الكتاب الثيعة الإيرانيين في الثي

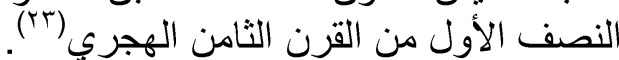

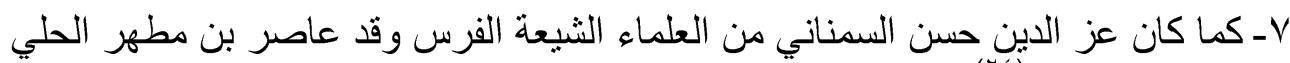

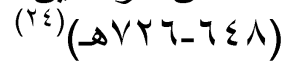

حركات التصوف

ظهر التصوف منذ القرون الإسلامية الأولى على أساس من العرفان والمحبة

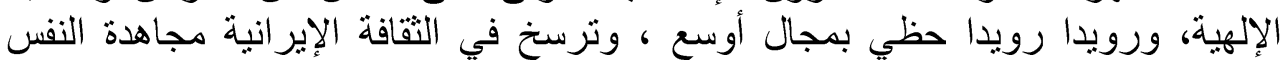

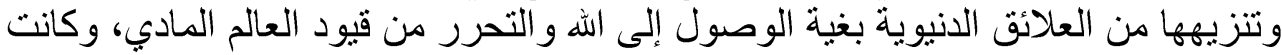

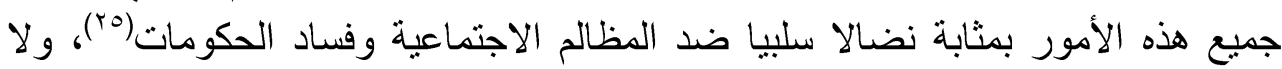

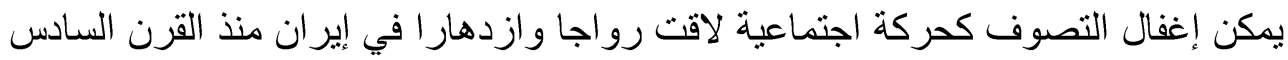

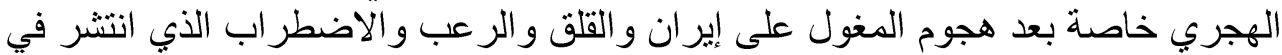
المجتمع الإيراني إثر هجماتهم و غار اتهم فلجأ الناس إلى التصوف التصوف ليهون عليهح المصائب

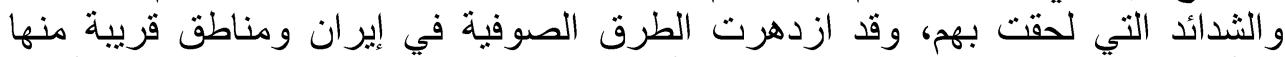

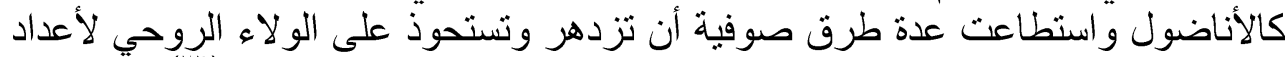

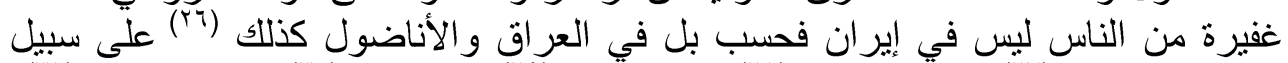

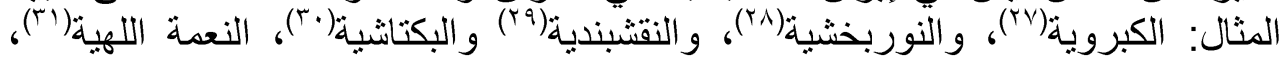

و الطريقة الصفوية في أردبيلث

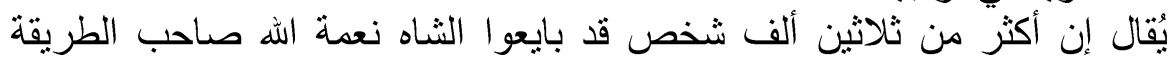

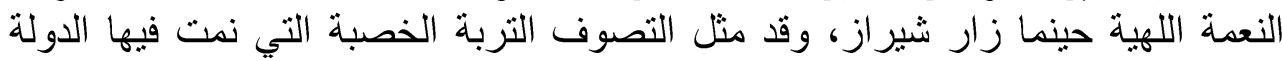

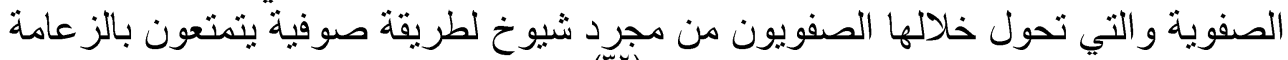

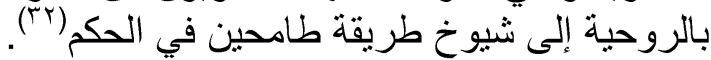

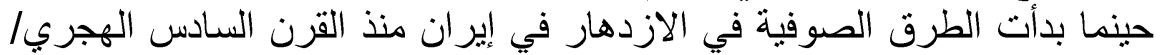

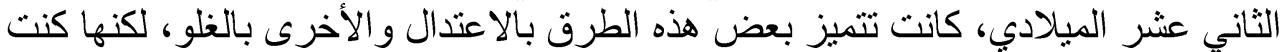

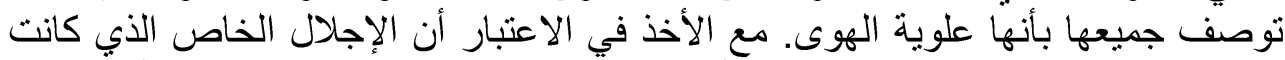

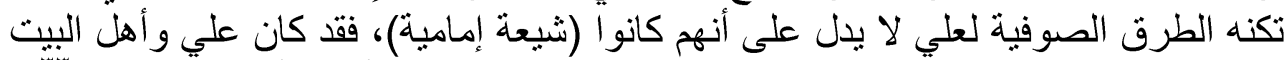

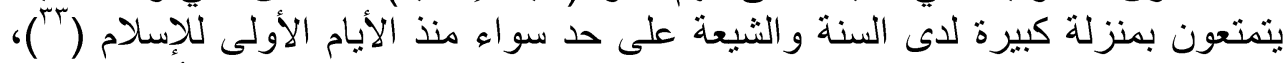

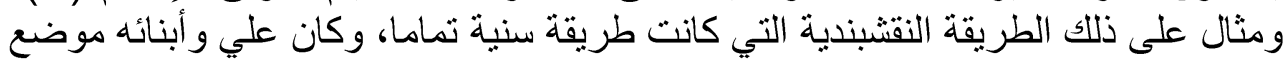

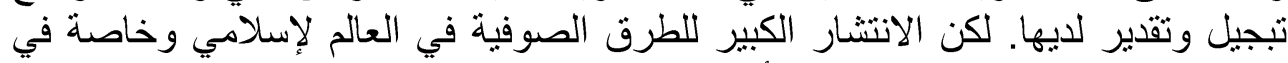

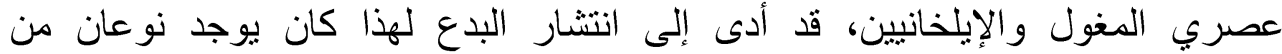

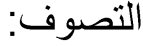

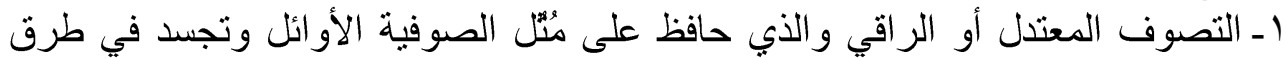
سنية معتدلة كالمولوية المنتشرة في الأناضول والي والنقشبندية المنتشرة في بلاد ما وراء

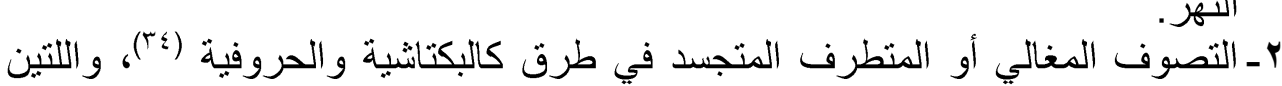

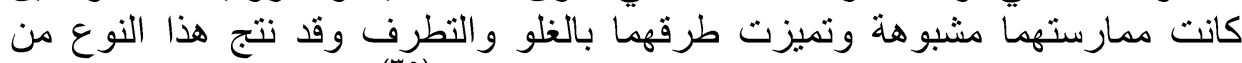

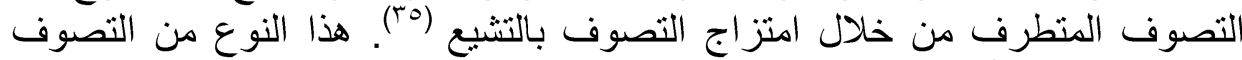

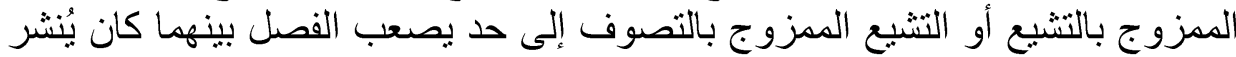


من خلال الفرق الصوفية بشكل خاص، ويمكن أن بطلق عليه بالفارسية "تشيع طريقتي"

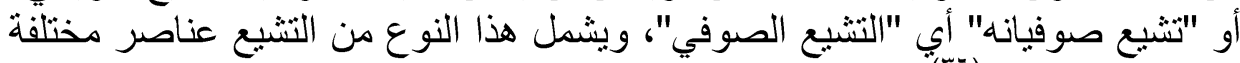

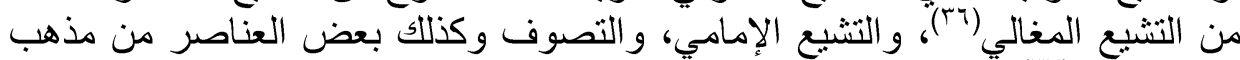

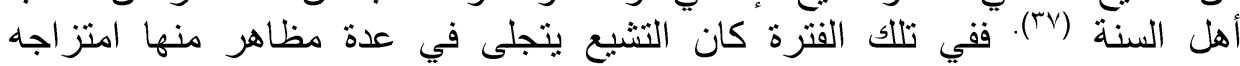

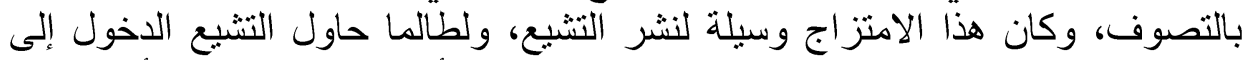

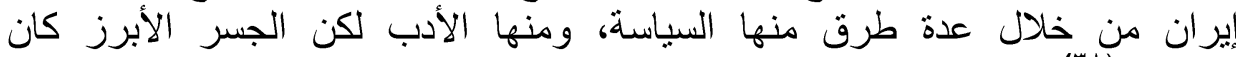

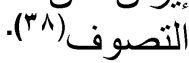

جدير بالذكر أن الإمام علي بن أبي طالب(كرم الله وجهه) كان من الأمور

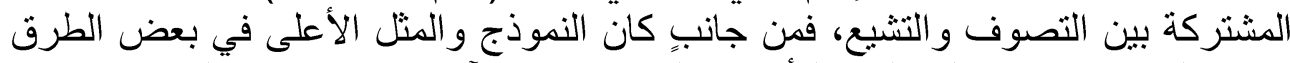

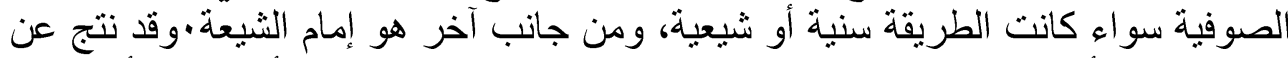

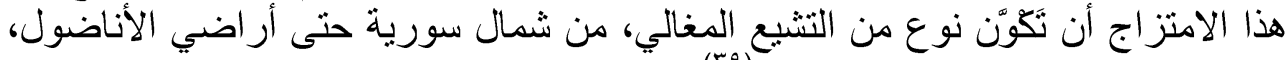

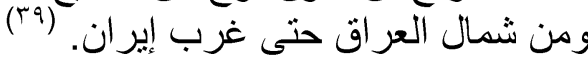

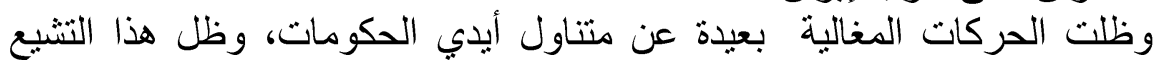

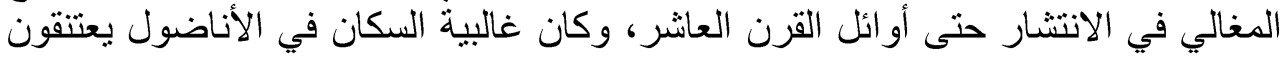

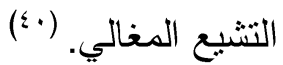

ويكمن سبب اتجاه هذه الحركات إلى التشيع فيما يقوله ميشيل مز اوي في كنابه إبهابه

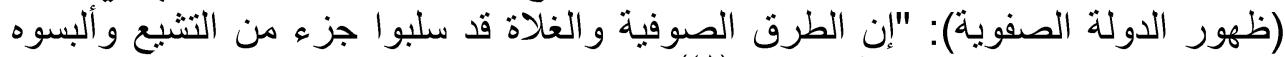

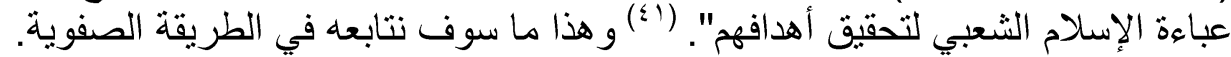

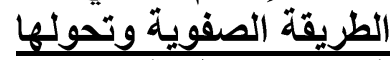

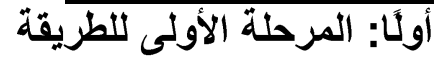

من خلال متابعة الطريقة الصفوية نجد أنها مرت بمرحلة الطنين، المرحلة الأولى تبدأ

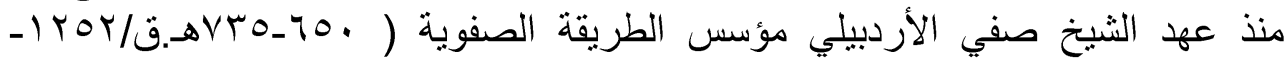

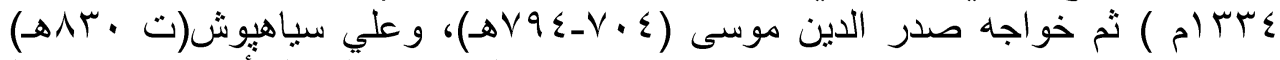

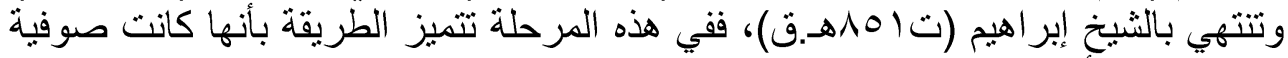

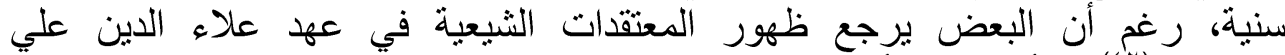

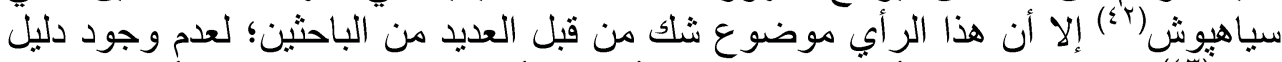

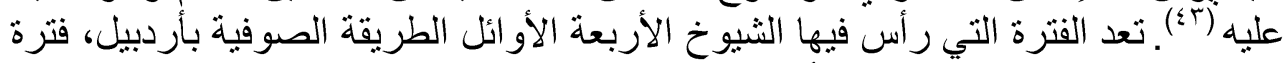

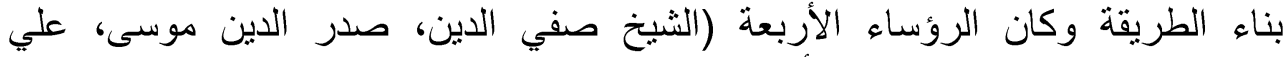

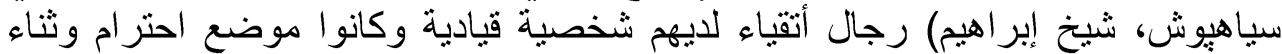

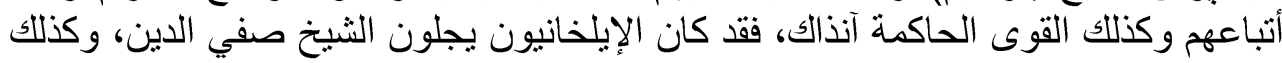

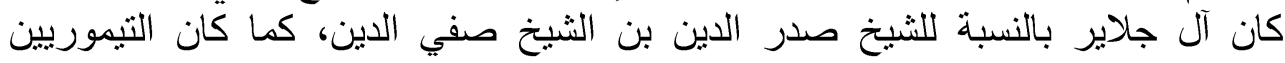

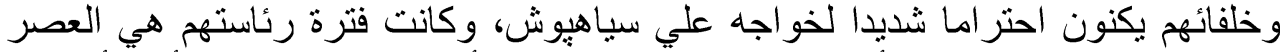

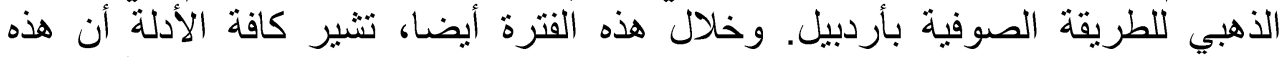

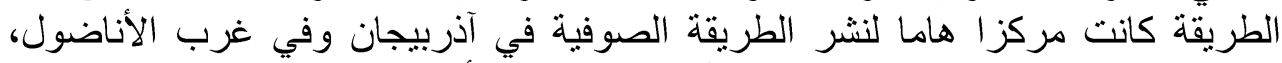

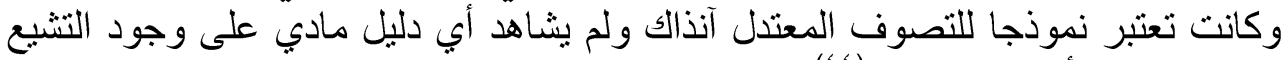

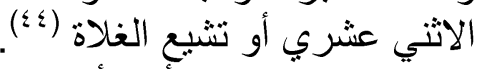

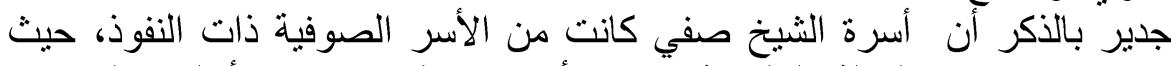

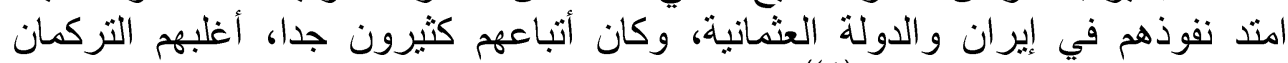

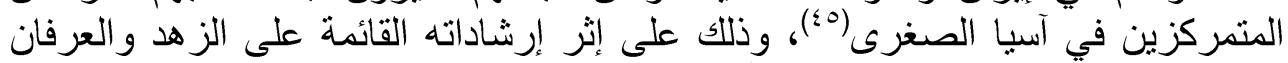
ورغبته وتصميمه في تربية مريدين أتقباء ، وتتضح مكانة صفي الدين في كتابات رشيد الترانه 


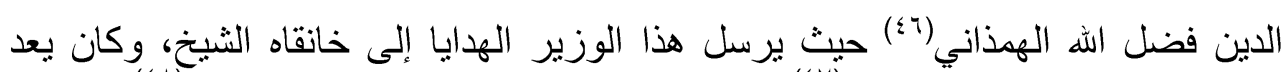

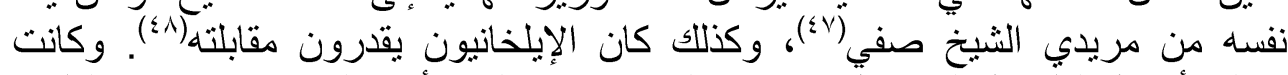

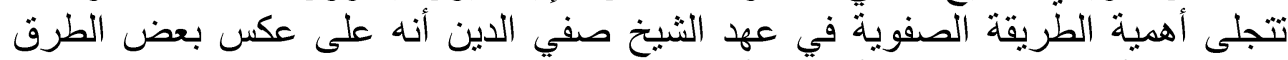

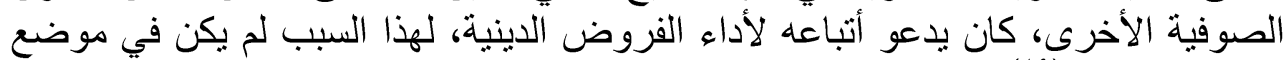

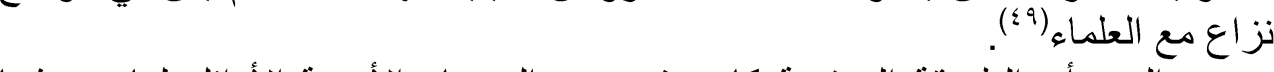

المهم أن الطريقة الصفوية كانت في عهد الرؤساء الأربعة الأوائل لها، نموذجا

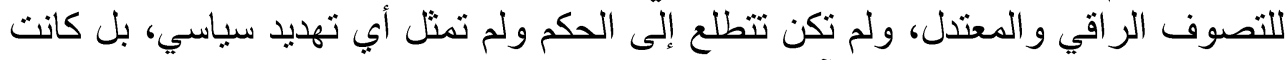

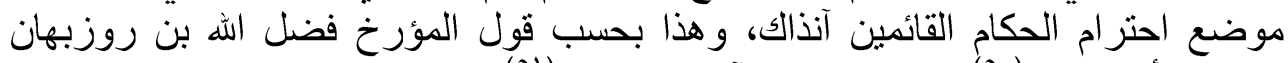

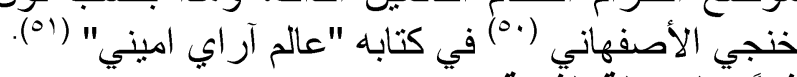

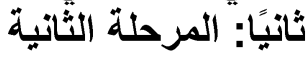

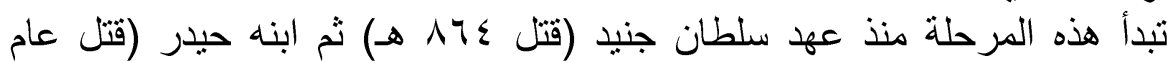

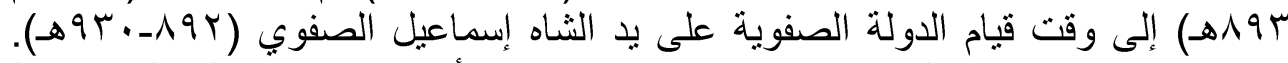

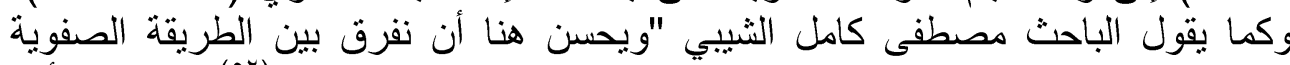

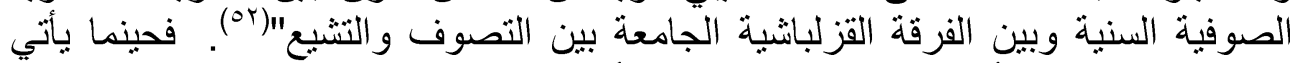

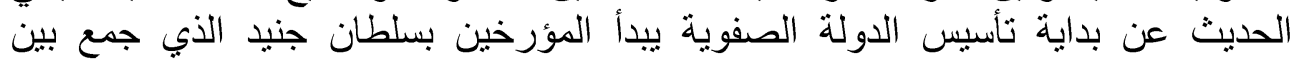

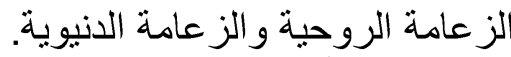
بعد أن ثوفي الثيخ إبراهيم، الثيونة تخوف جهانشاه حاكم القر اقويونلو من أن يتولى الثيخ

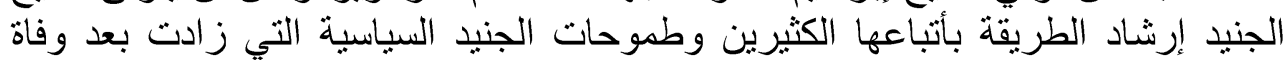

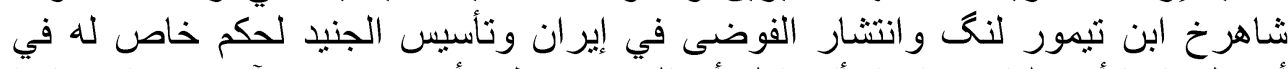

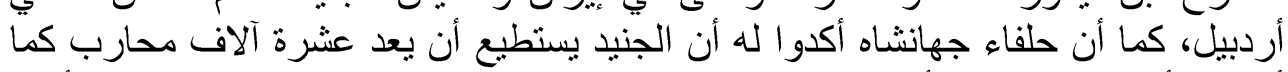

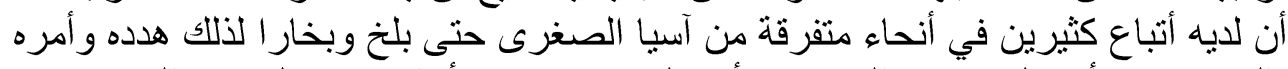

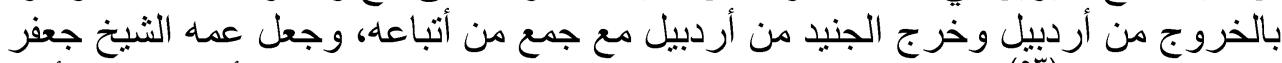

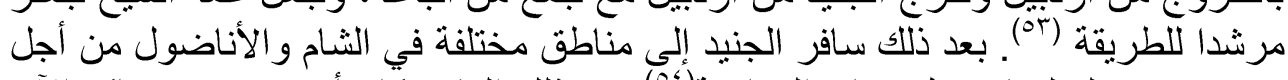

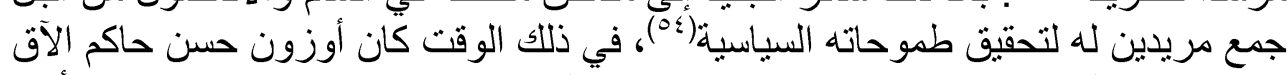

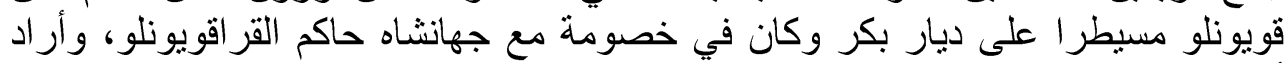

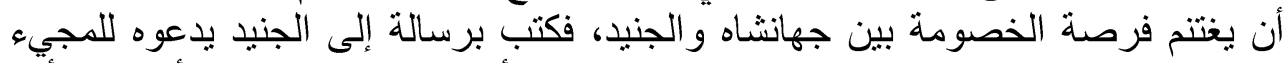

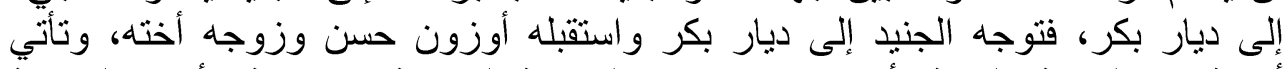

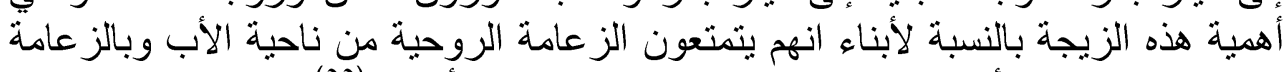

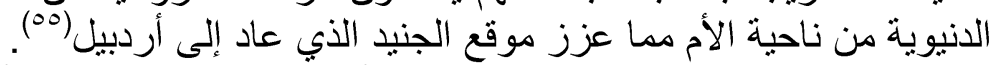

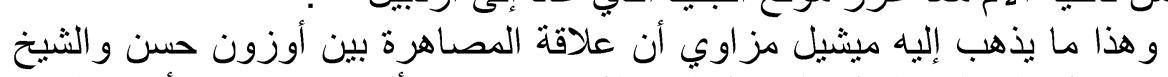

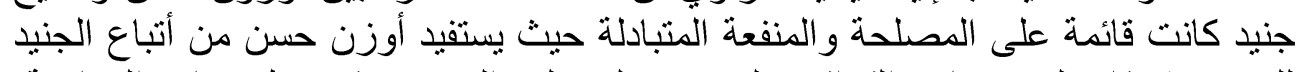

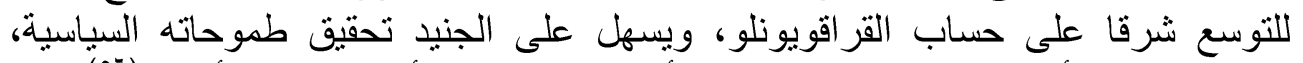

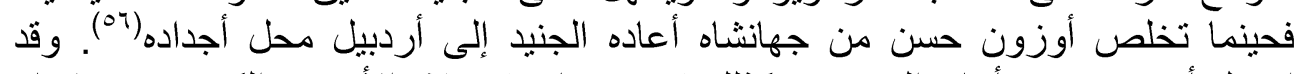

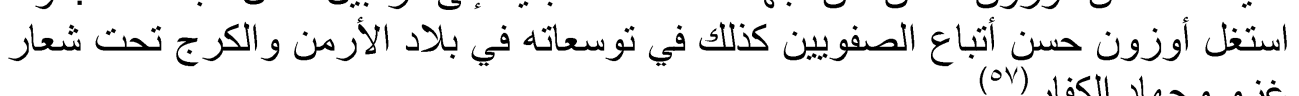

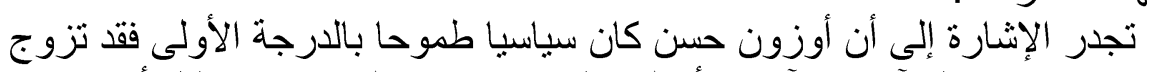

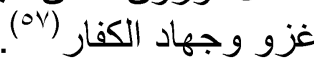

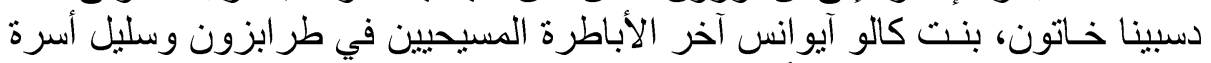

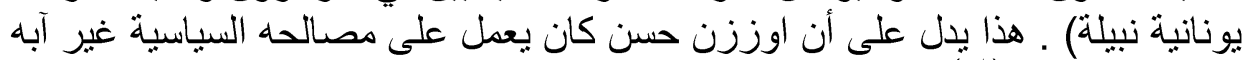
بالمذهب أو الدين (ON) 
في عهر الثيخ الجنيد تحولت الطريقة من طريقة سنية صوفية إلى طريقة تتبنى التهل

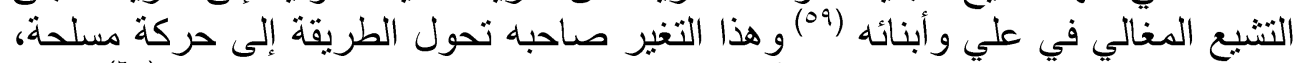

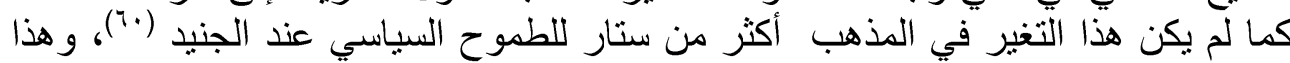

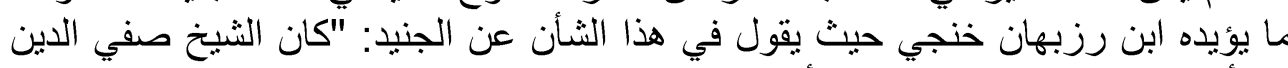

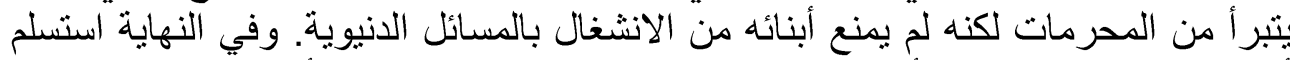

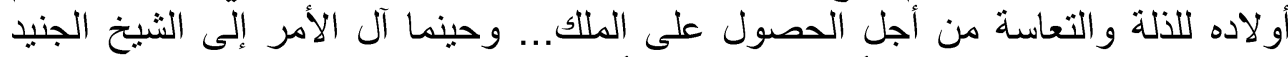

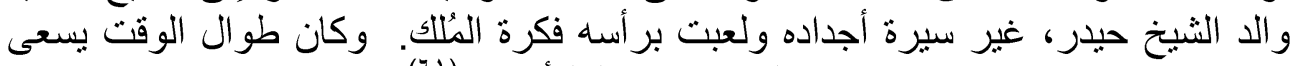

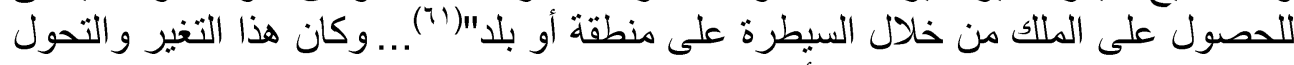

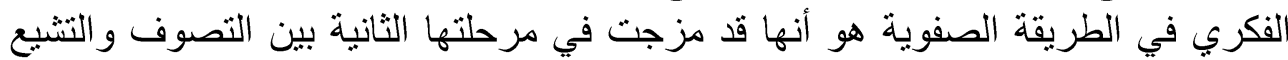

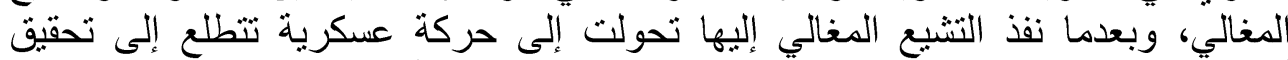

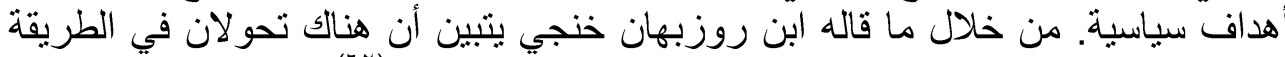

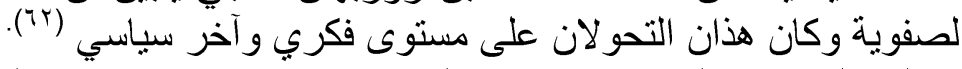

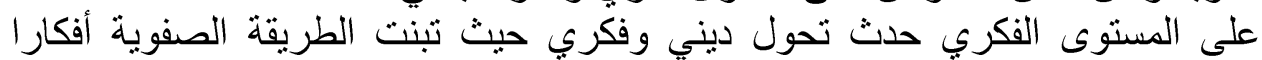

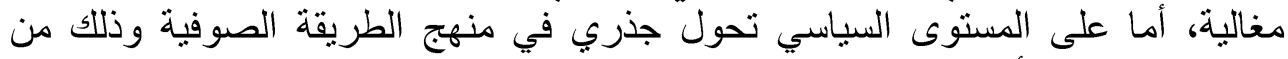

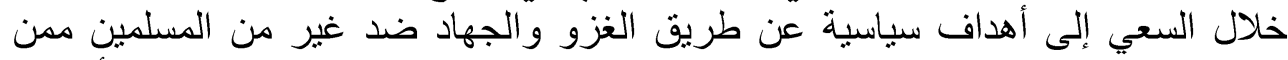

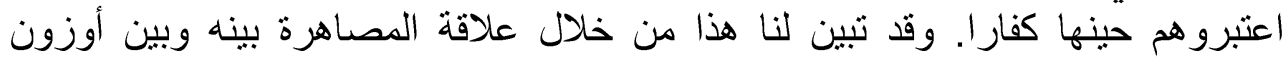

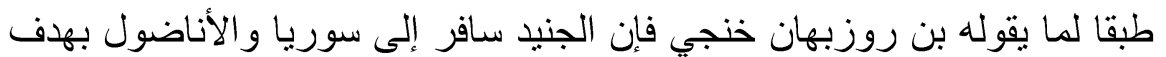

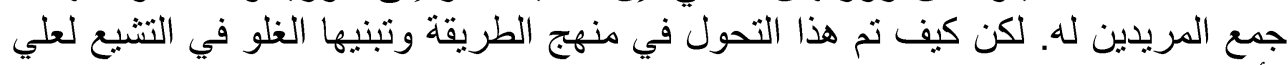

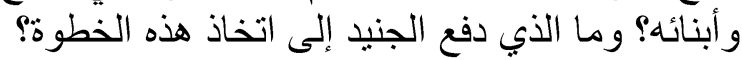

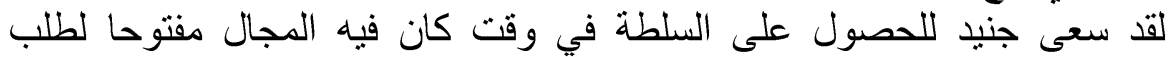
السلطة وإقامة الدويلات بعد انهيار الإمبراطورية التيمورية بوفاة شاهرخ، والفية وازدهار

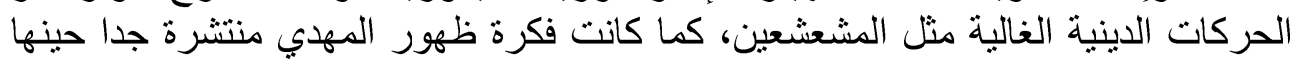

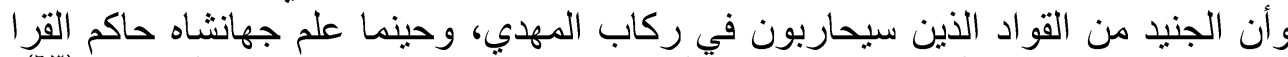

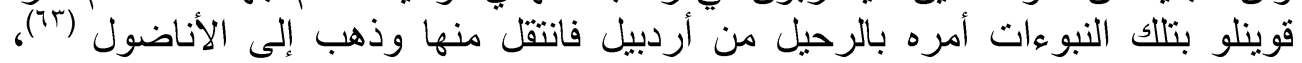

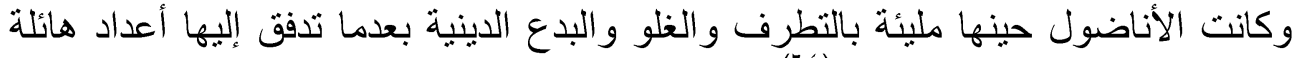

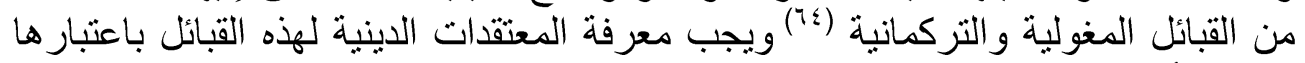
النواة الأصلية للدولة الصفوية والتي ظلت الت طوانة الت القرنيين السابع والثامن الهجريين تتبنى معتقدات غالية ومتطر فة (70)

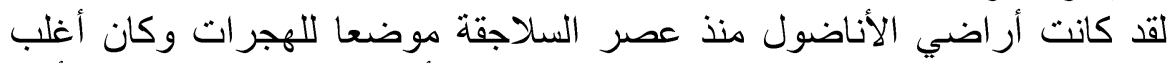

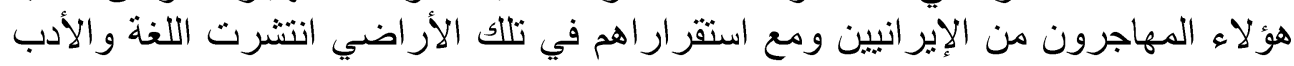

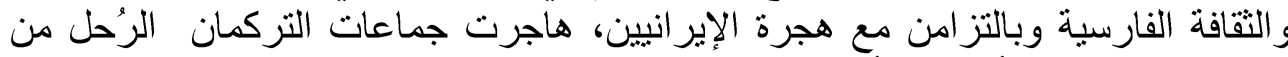

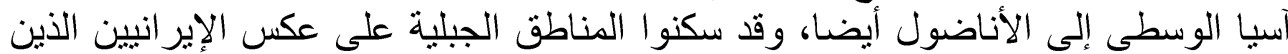

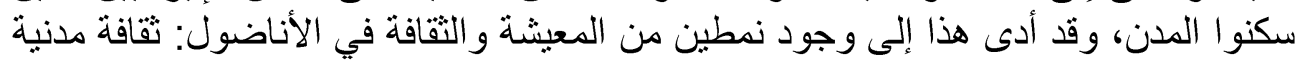

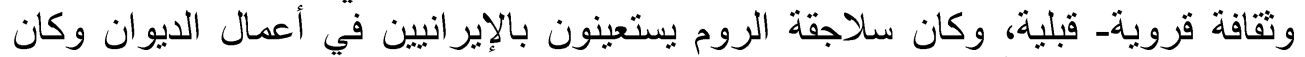

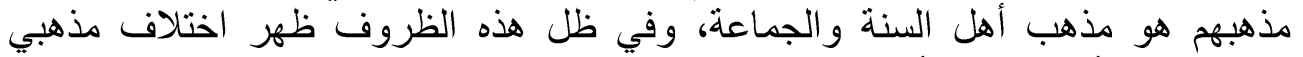

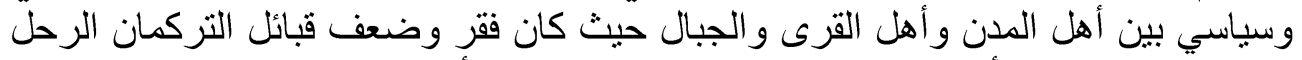

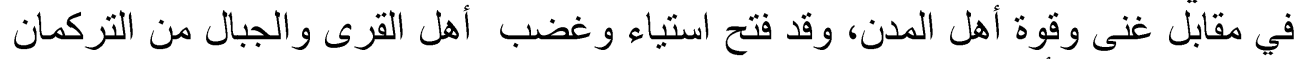

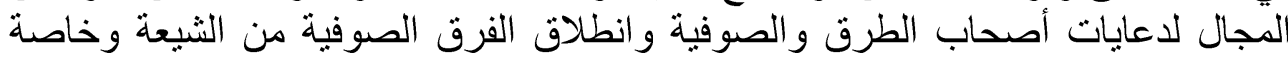

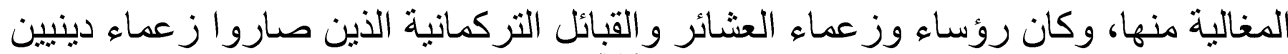

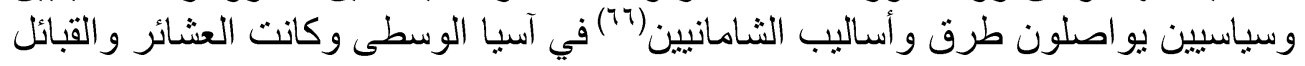


ترى من الواجب طاعتهم، وقد قامو ا بعدة حركات وثورات اجتماعية قضى عليها السلاجقة

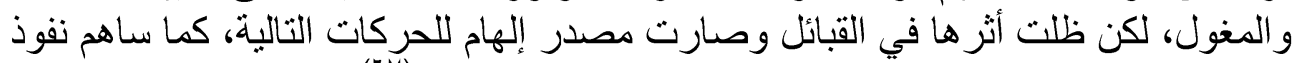

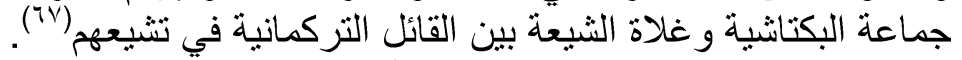

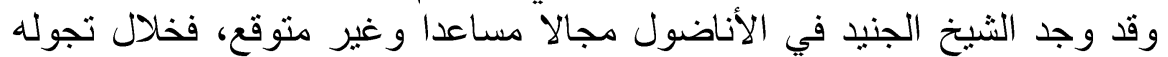

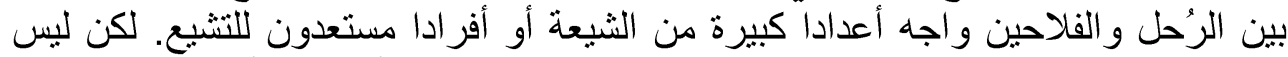

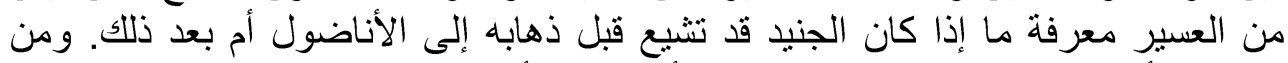

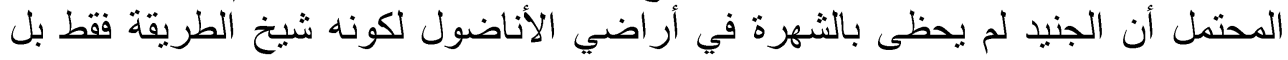

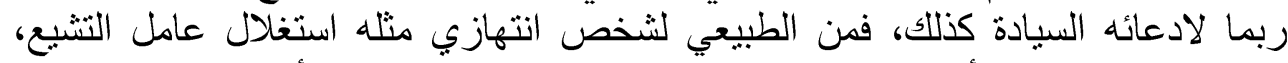

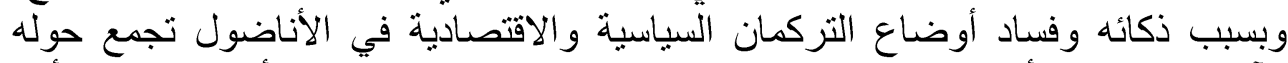

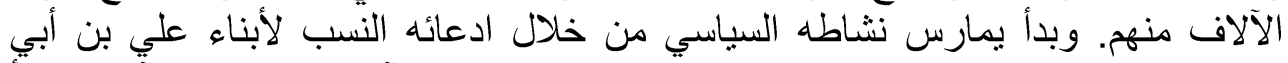

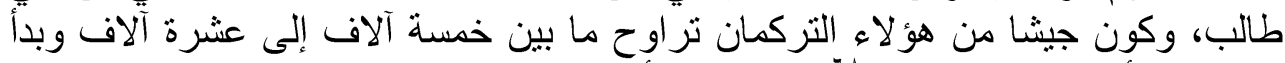

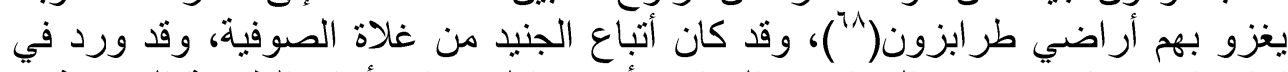

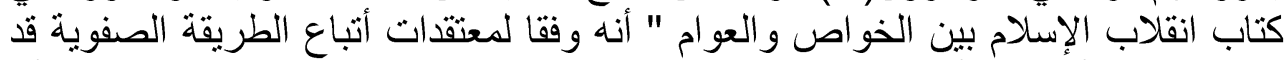

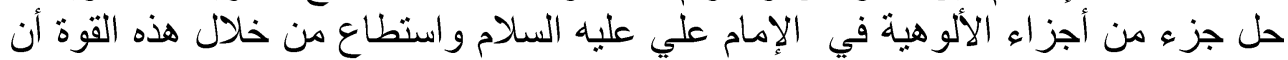

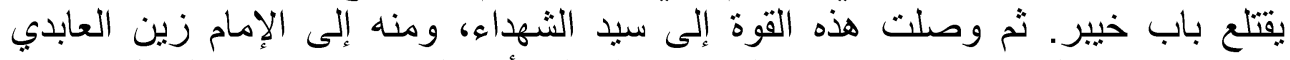

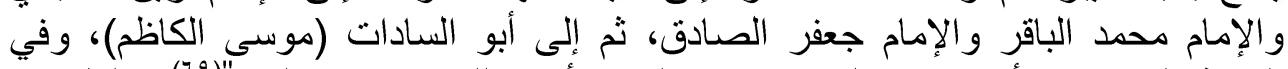

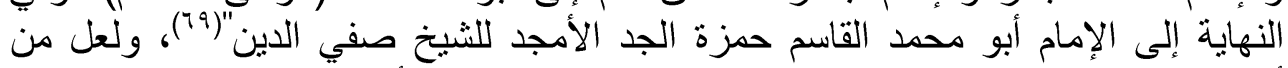

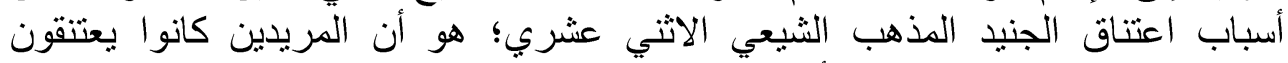

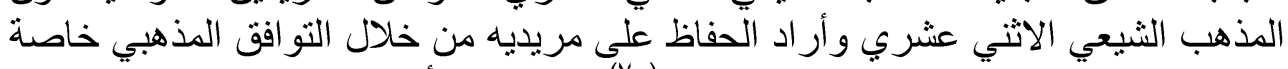

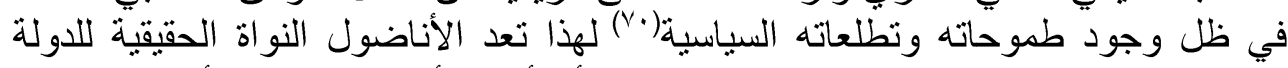

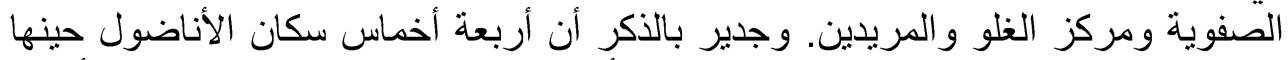

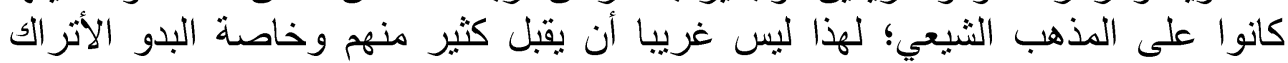

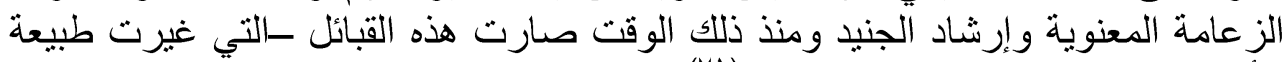

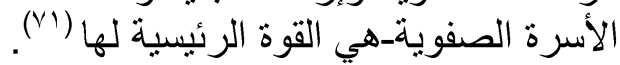

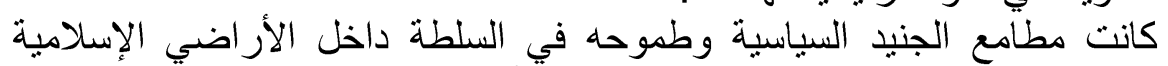

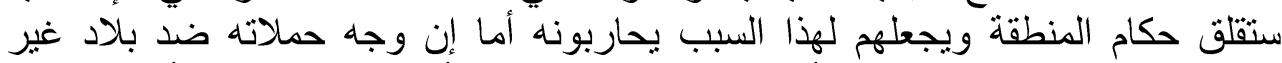

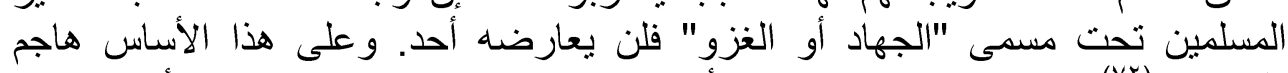

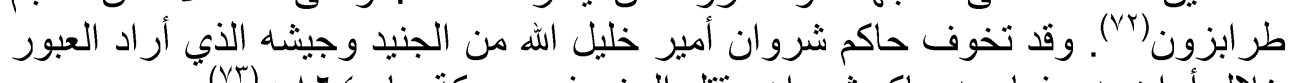

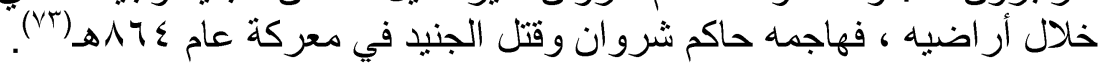

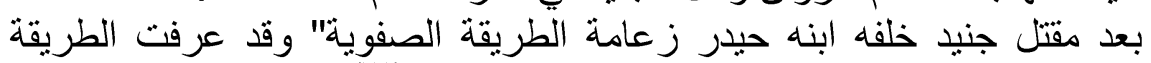

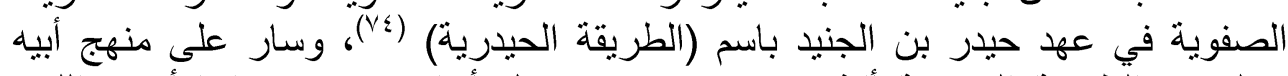

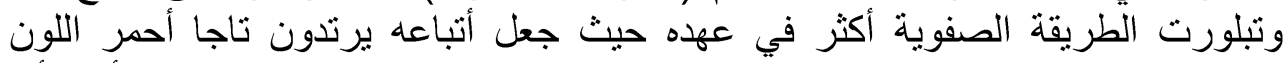

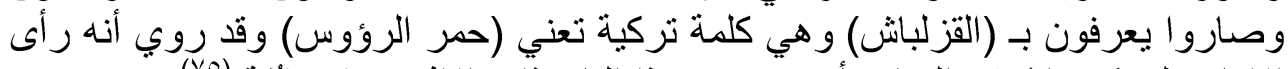

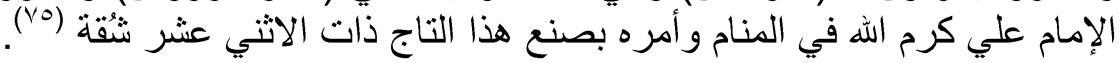

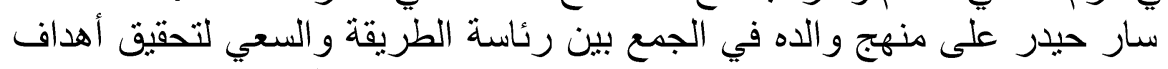

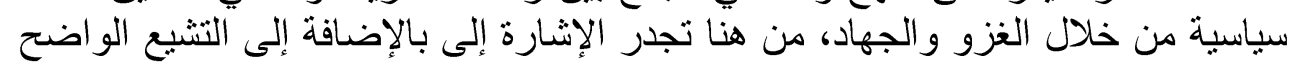

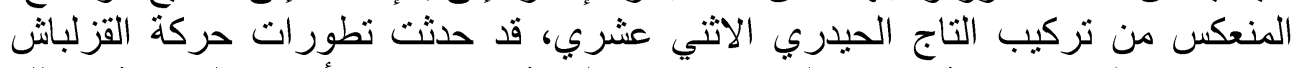

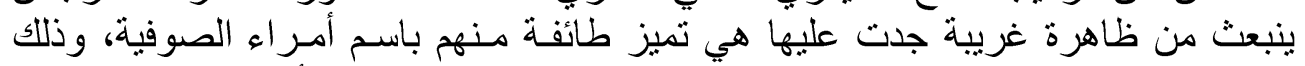

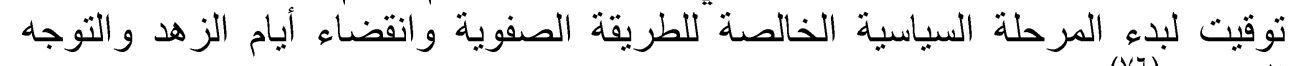




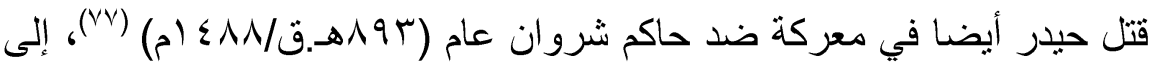

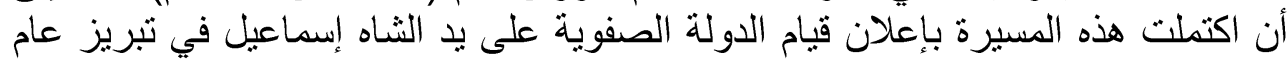

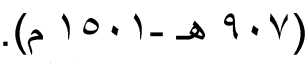

تعتبر الطريقة الصفوية في مرحلتها الثانية نموذجا لهذا النوع من التصوف التهوف الذي التئي

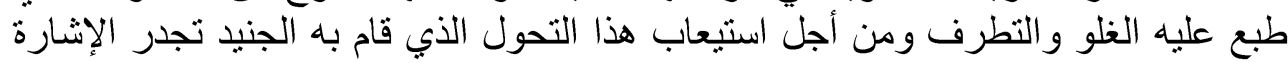

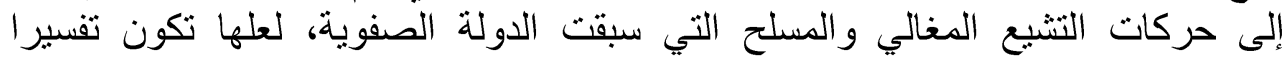
وتوضيحا جيدا لهذا التحول.

\section{حركات التشيع المغالى (غلاة الثيعة) قبل الدولئة الصفوية الصنية}

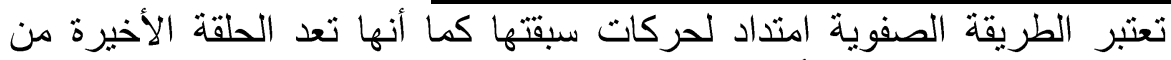

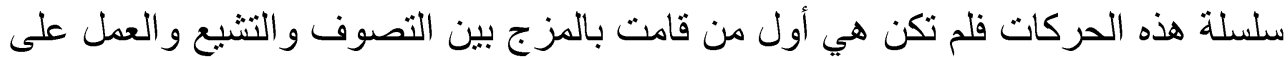

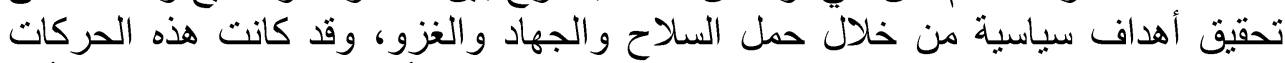

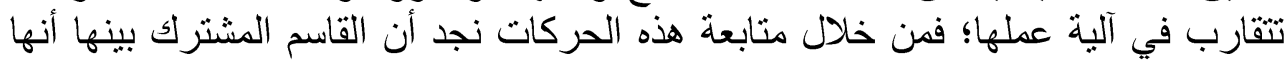

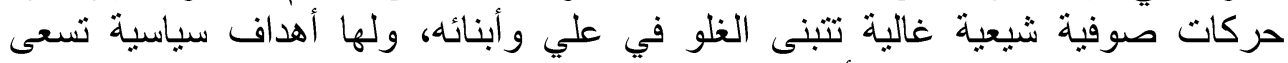

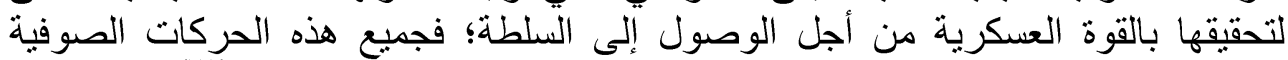

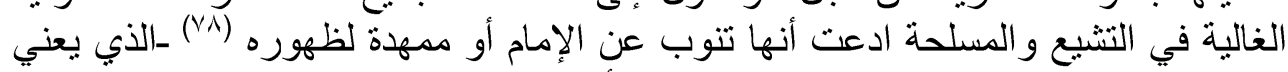

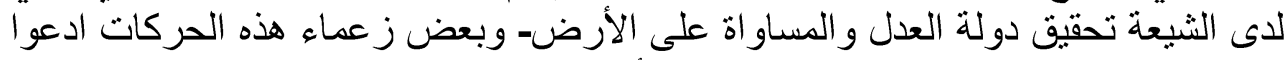

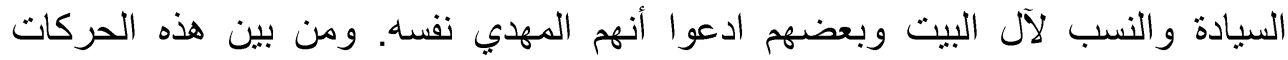

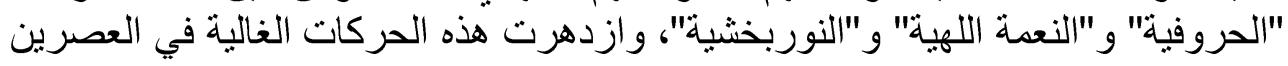

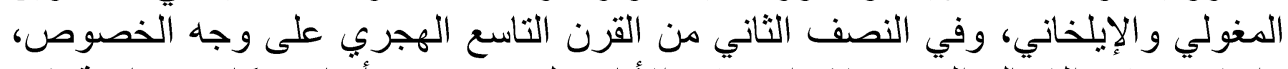

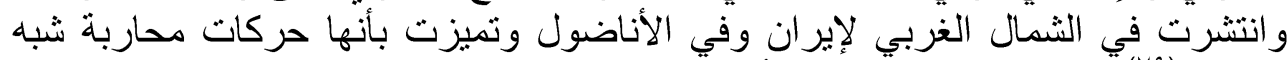

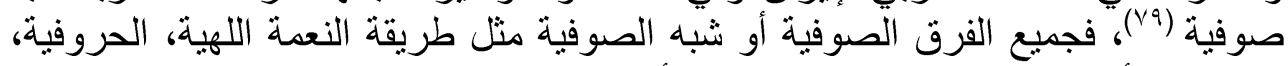

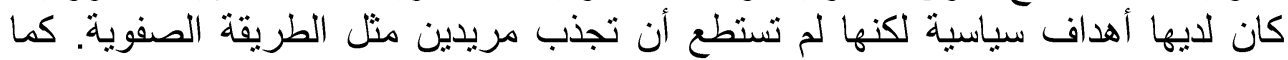

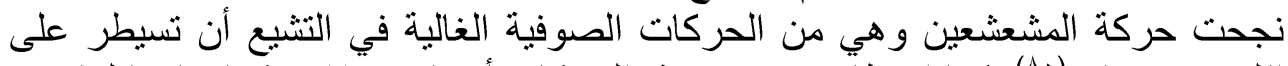

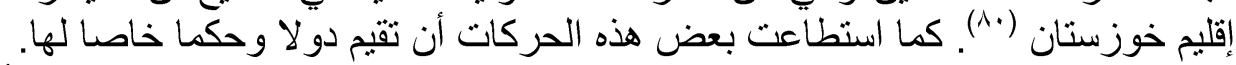

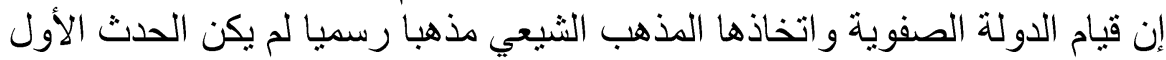

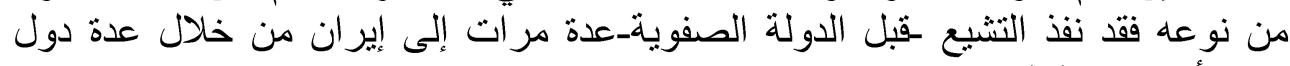
كانت أبرز ها كالتالي:

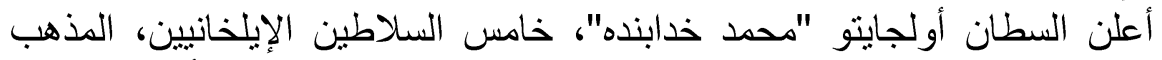

الثيعي الاثثي عشري مذهبا رسميا في إيران في عام (

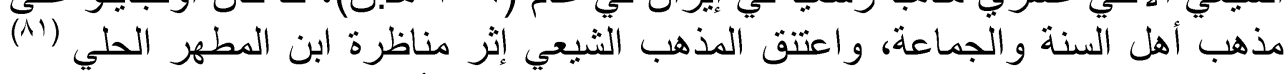

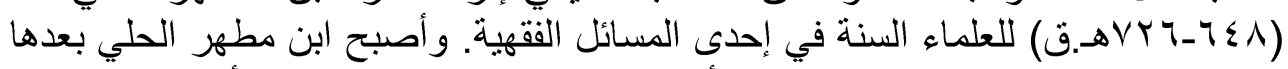

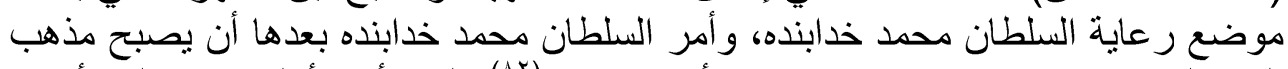

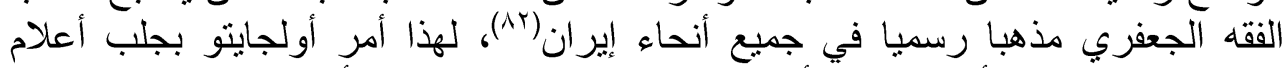

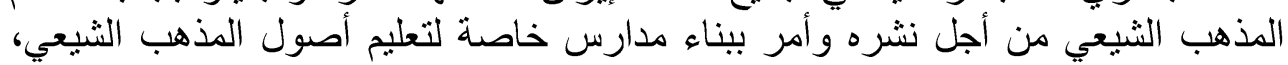

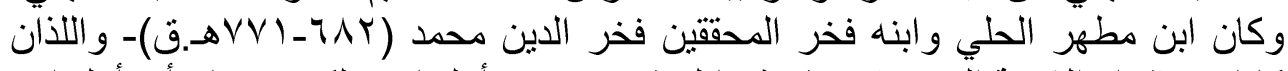

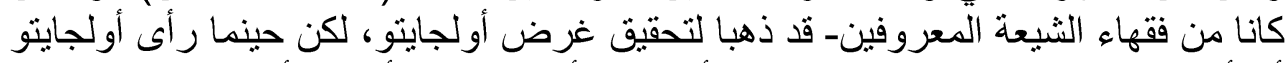

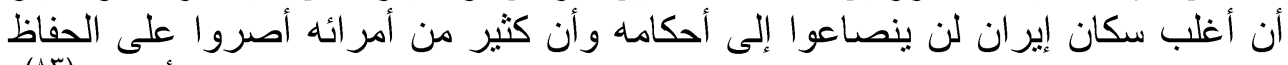

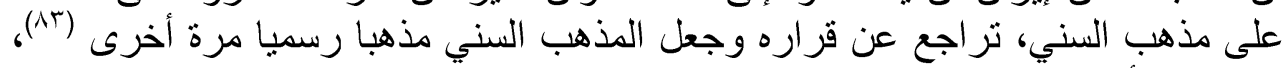

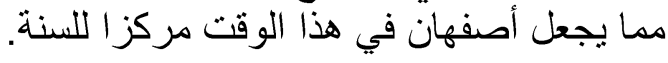




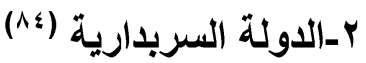

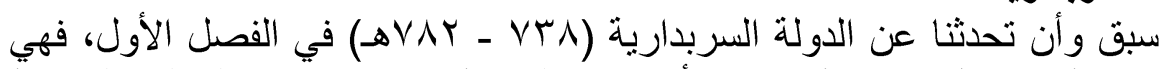

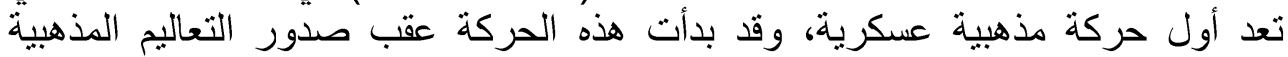

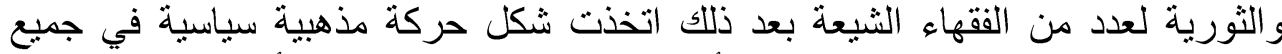

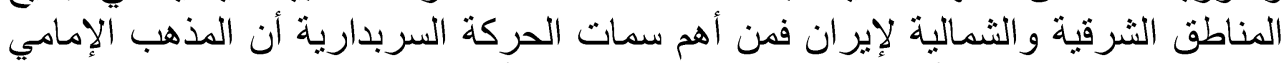

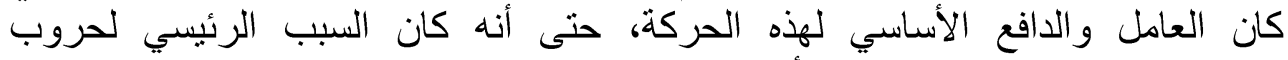

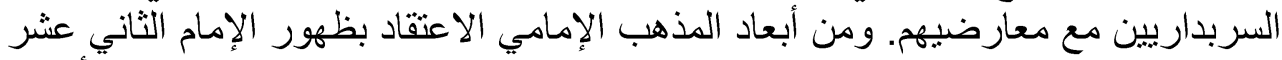

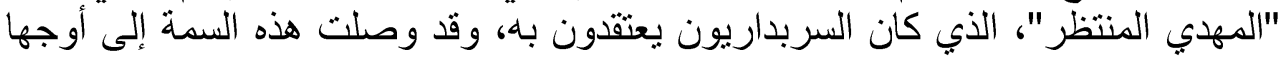

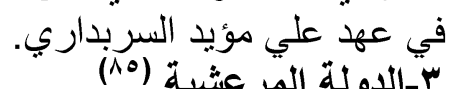

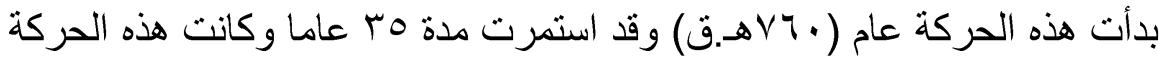

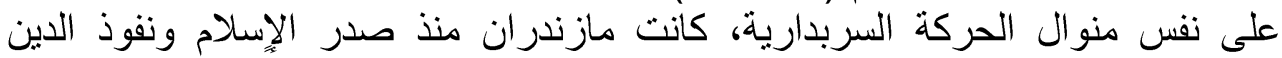

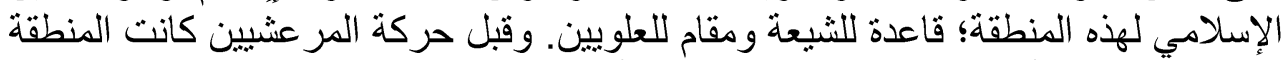

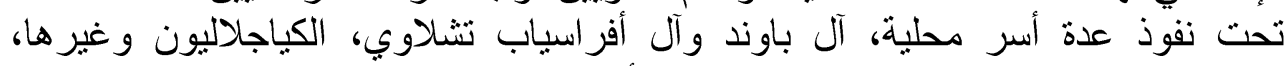

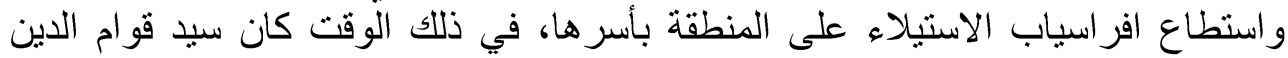

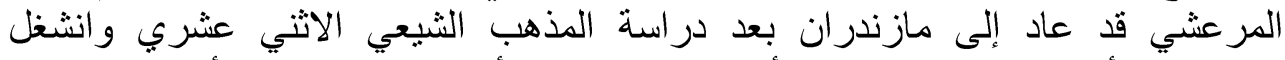

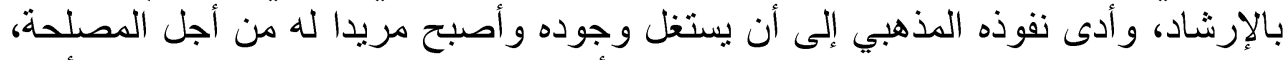

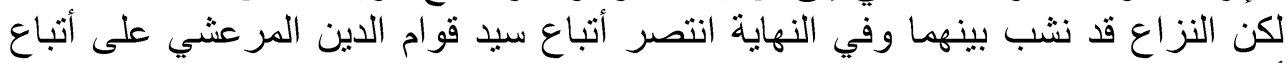

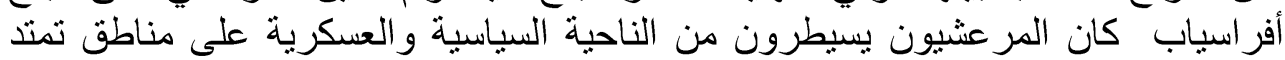

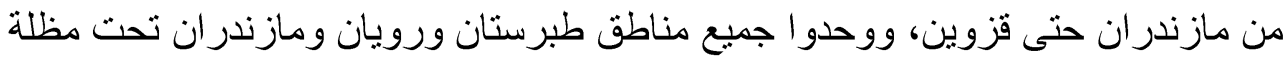

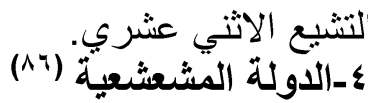

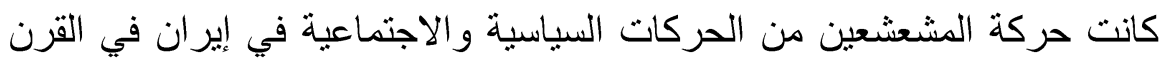

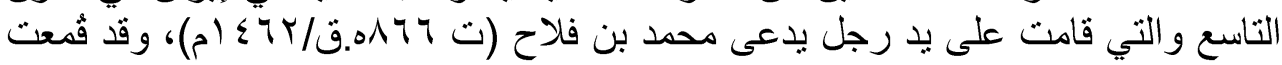

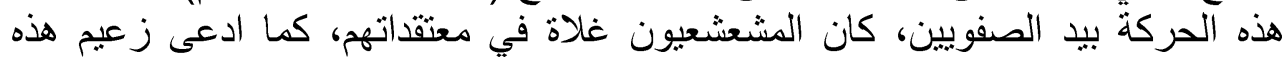

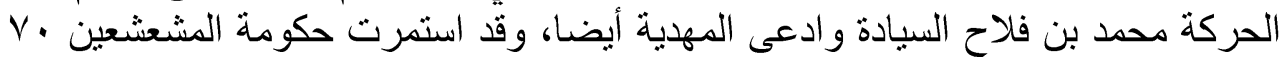

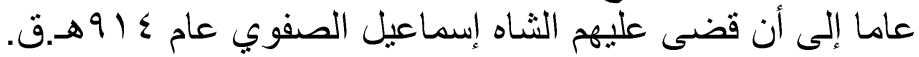

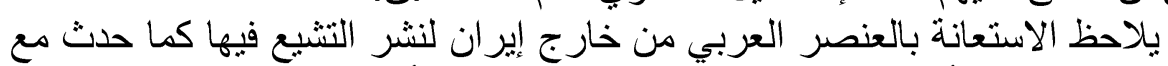

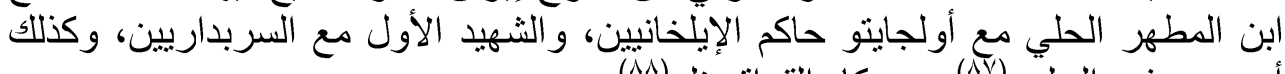

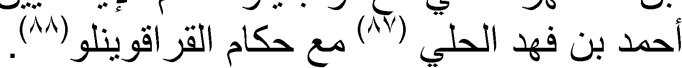

بعدما استعرضنا الأحوال و الظروف التي سبقت قيام الدولة الصفوية والتي هيأت

الخاتمة

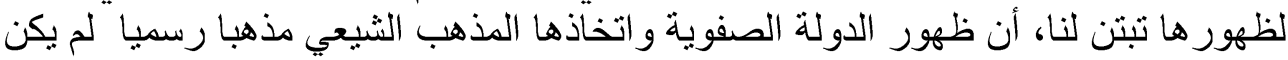

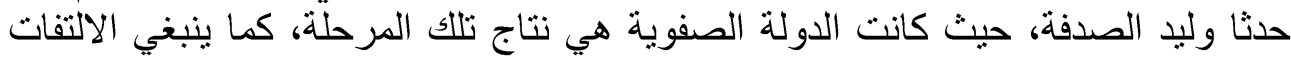

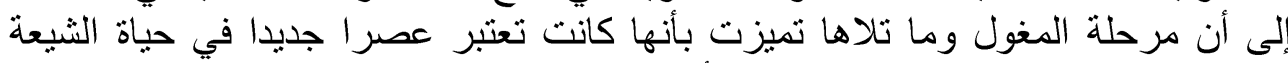

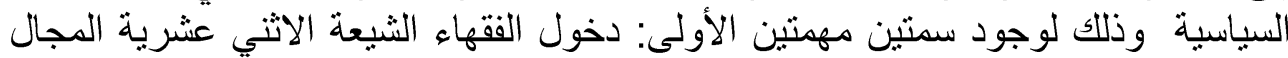

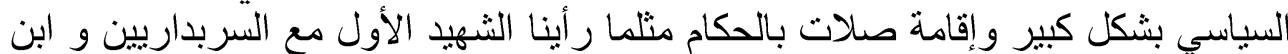

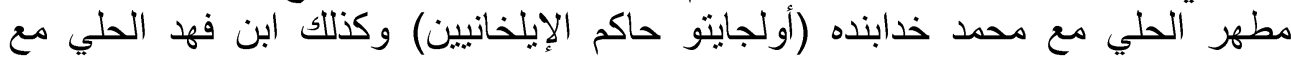

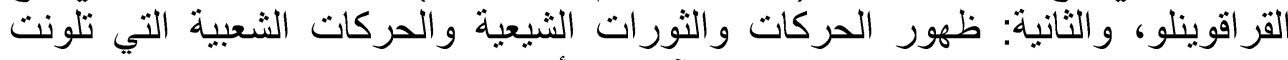
بلون المذهب الثيعي الاثني عشري كانت آخرها وأنجحها الحركة الصفوية. 


\section{Abstract \\ Political and religious conditions in Iran prior to the establishment of the Safavid state \\ By Amr El Sayed Ali El Sayed}

Before the establishment of the Safavid dynasty in Iran there were social and political conditions, which ensured the success of this dynasty and appearing on the political scene in the Islamic East. This country was founded on a religious basis, where taken from the Twelver school of Shi'a as the official religion of their empire. However, this was not surprising. As after the Mongol invasion of the Islamic homeland in the seventh century Hijri and multiplicity the ruling nations in Iran and the collapse of the Iranian society, there was a stream of mysticism, which flourished as a shelter for soul and spirit to this community, who has injury concerns due to acts of brutality and cruelty.

Some of these movements marked by moderation, others marked by extremism, fanaticism and mixing between mysticism and extremist Shi'a.

These movements spread with great influence, particularly in the areas of Iran and Anatolia. The absence of official religious institutions played a major role in the prosperity of these Sufi movements. Some of these Sufi movements take a political dimension not only asceticism. Some of these movements has been revolted on the local rulers as the Alserbdarien movement in Khorasan, and established state for them.

In addition, there was the Ilkhanid dynasty -that preceded it- and its ruler "Mohammed Khuddabandh" (Oljeitu) announced Shi'ism as the official religion of their empire, but the people of Isfahan rejected this decision, so he obliged to back again to the Sunni doctrine.

As well as the State of Mar'ashi in Mazandaran was on the basis of Twelver Shi'ism, and the State of Musha'sha'iyyah in Khuzestan.

If we review the sectarian map of Iran before the establishment of the Safavid dynasty, we will find the predominance of the Sunni doctrine on Iranian regions, and the presence of Shi'a minorities only in some cities. However, this does not deny the link between Shiism and Iran in this period, where Shiism tried to enter Iran through the many ways in which the most important was the 'mysticism'.

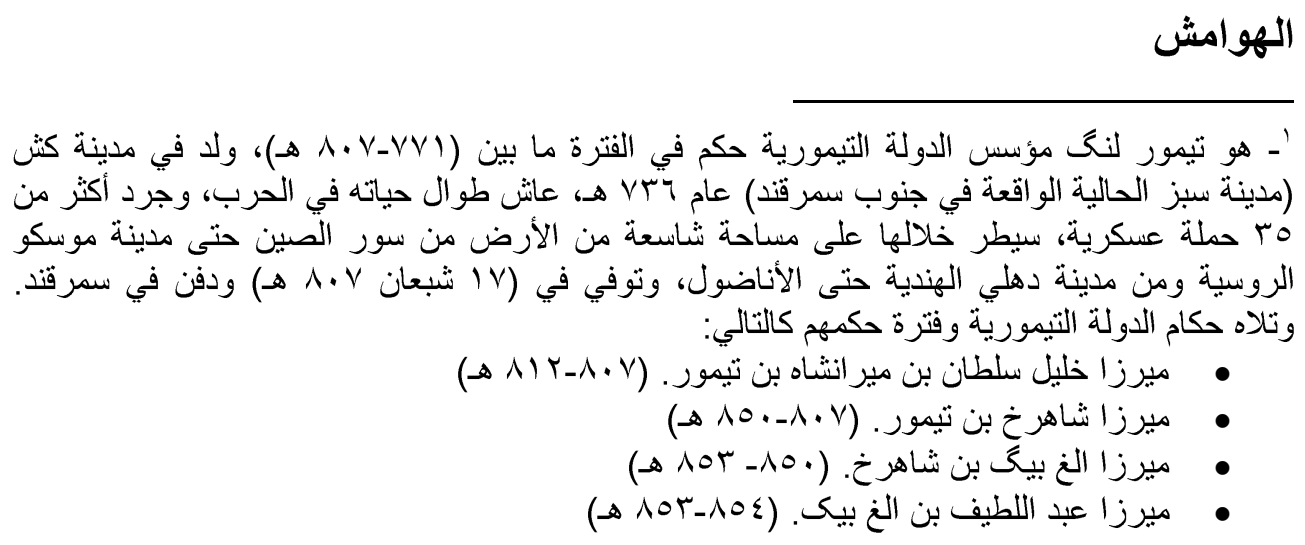




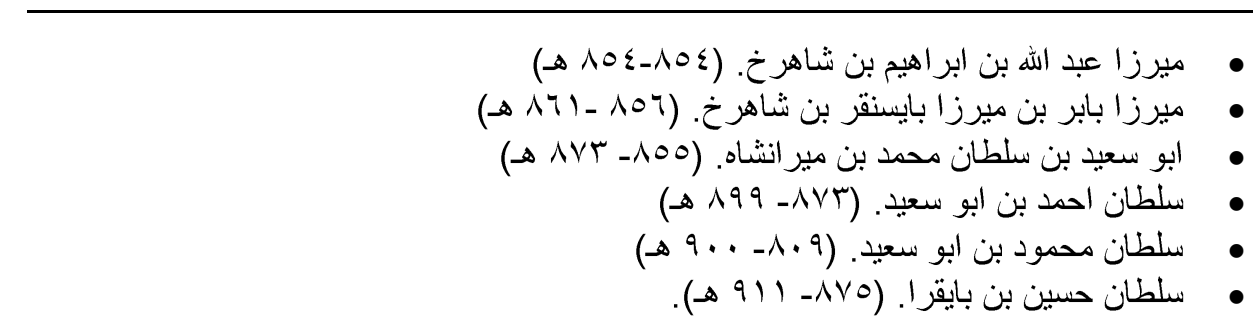

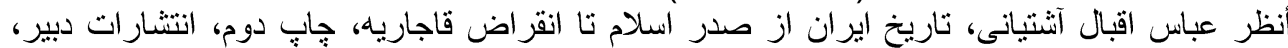

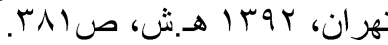

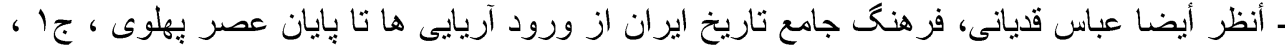

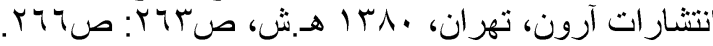

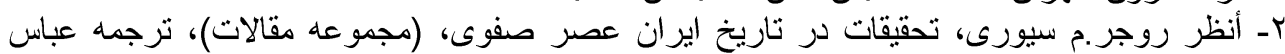

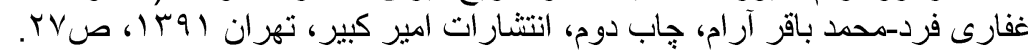

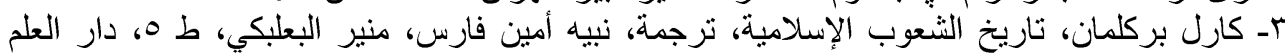

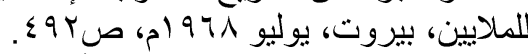

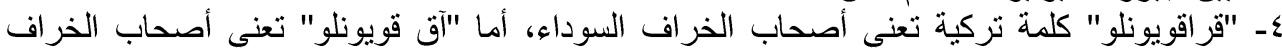

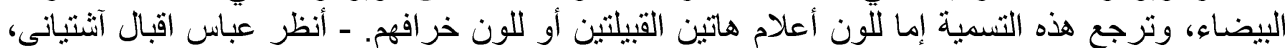

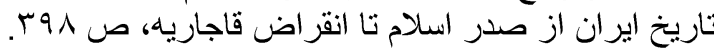

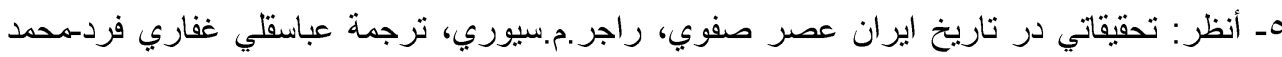

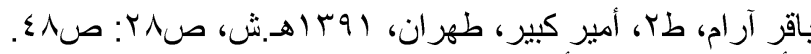

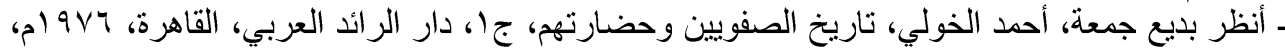

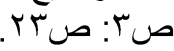

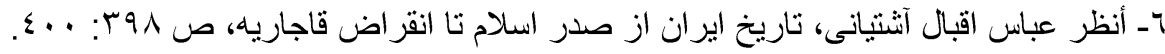

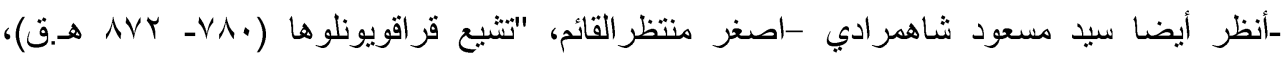

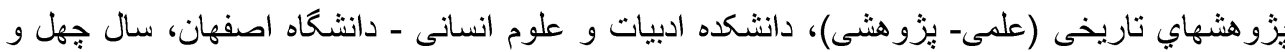

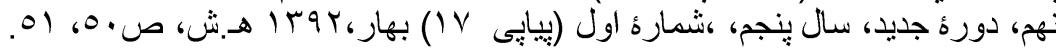
'- وتوالى على دورم هذه القبيلة الأمراء التاليين:

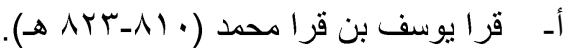

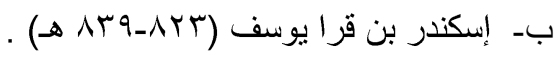

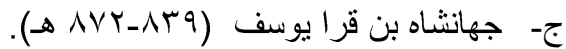

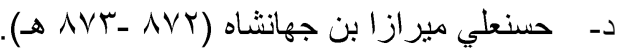

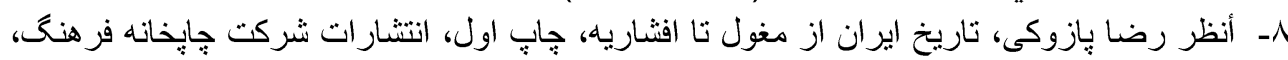

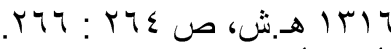

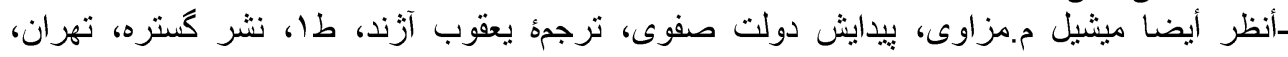

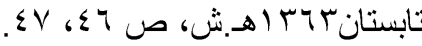

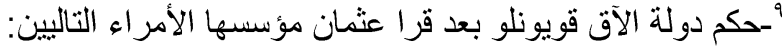

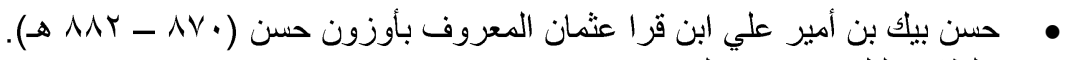

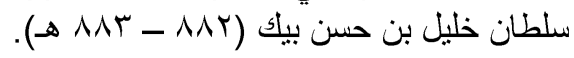

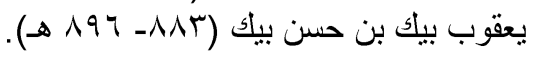

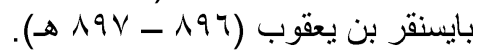

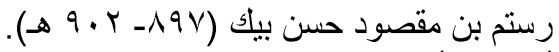

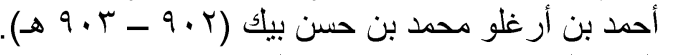

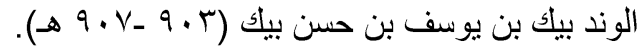




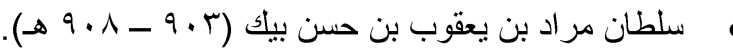

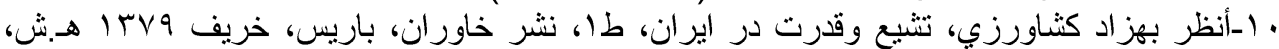

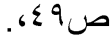

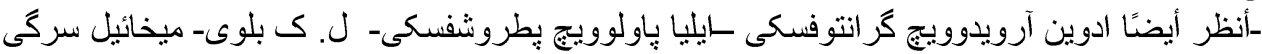

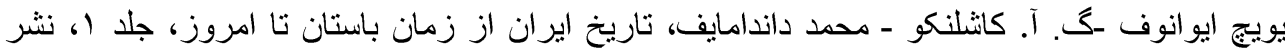

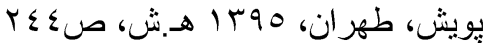

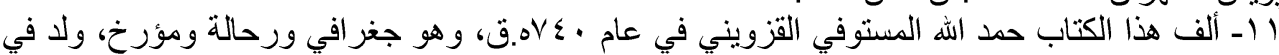

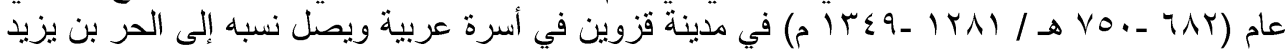

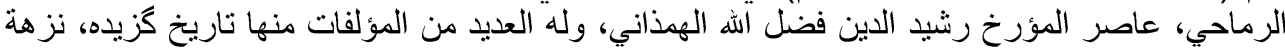

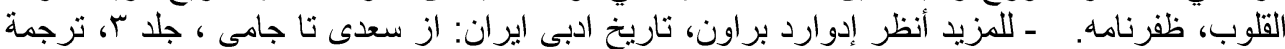

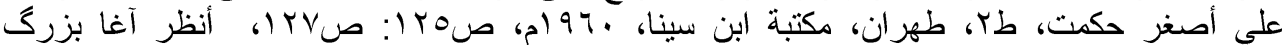

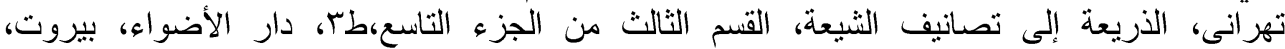

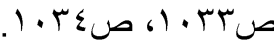

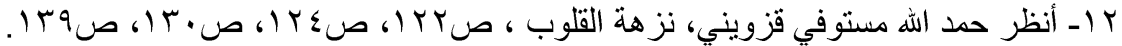

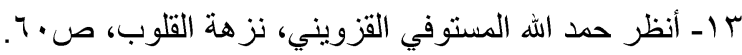

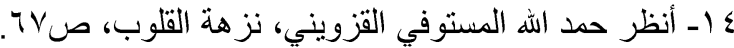

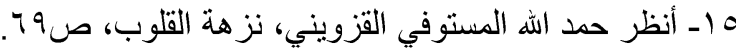

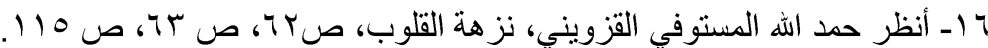

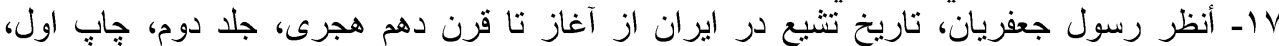

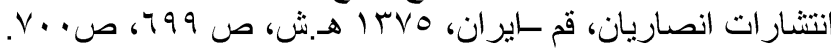

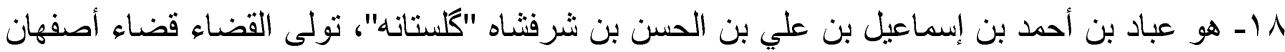

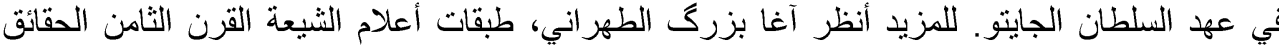

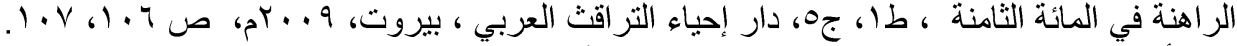

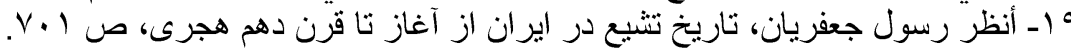

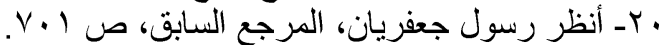

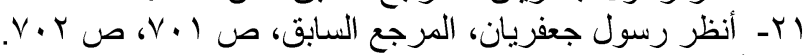

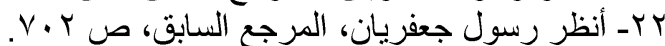

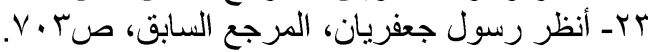

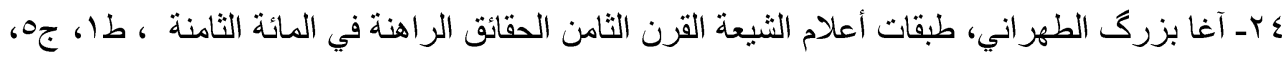

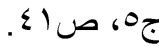

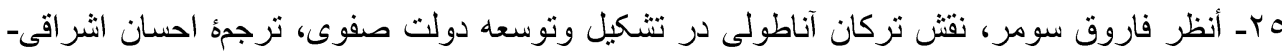

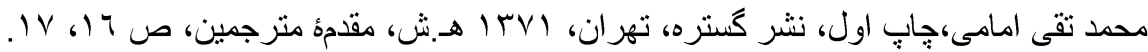

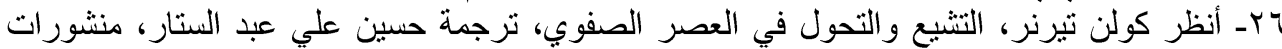

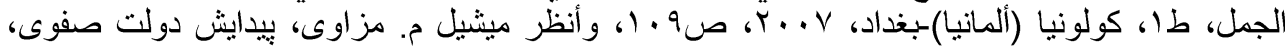

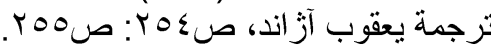

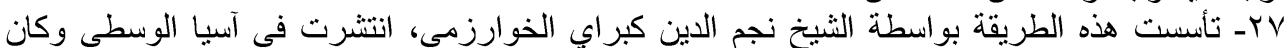

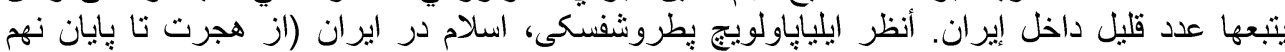

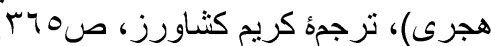

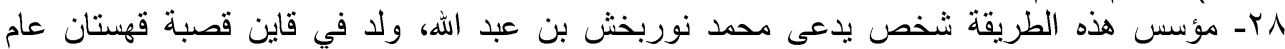

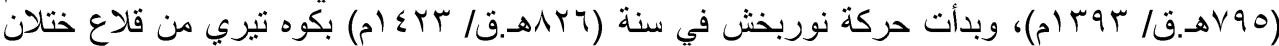

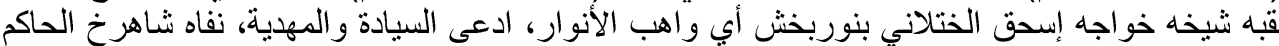

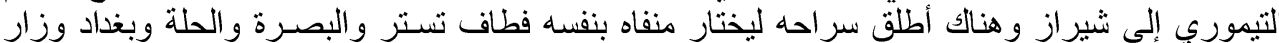

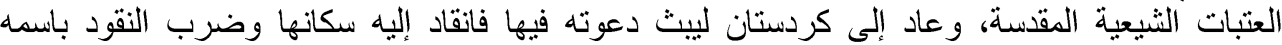
وتسبب ذلك في قلق شاهرخ من جديد، وانتهى الأمر بالقبض على نورئ نوربخش من جديد وسجن ومن ثم سير لفي 


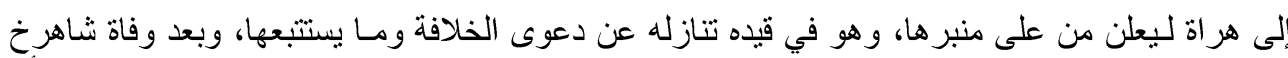

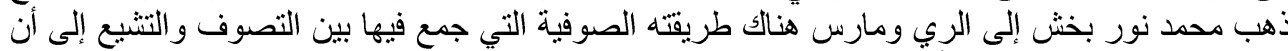

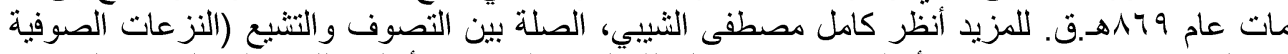
في التشيع) من بعد عصر الأئمة حتى سقوط الدولة الصفوية، دار الأندلس للطباعة والنشر والتوزيع،

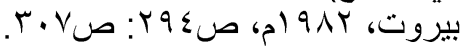

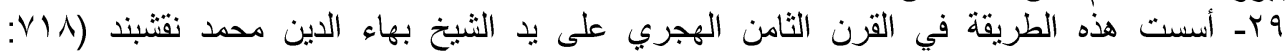

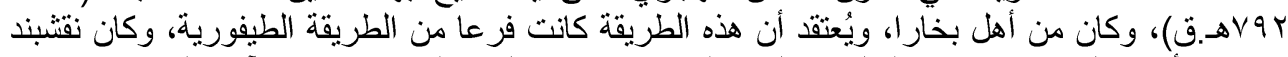

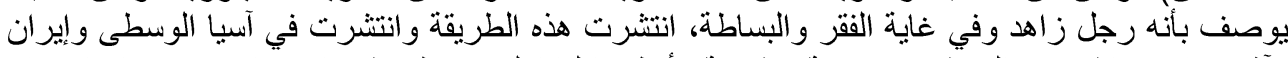

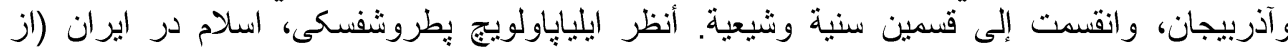

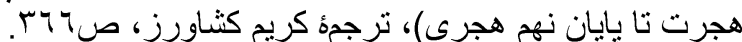

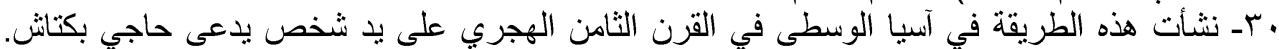

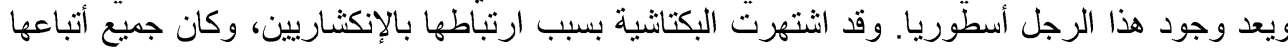

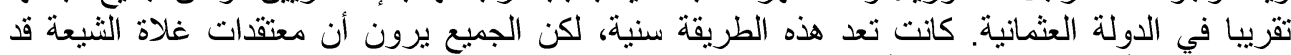

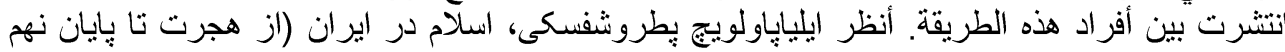

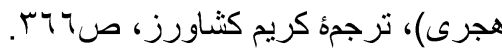

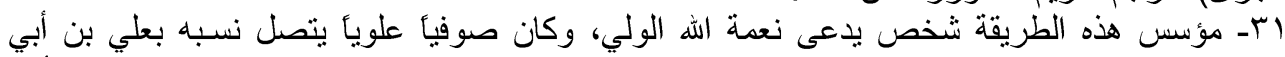

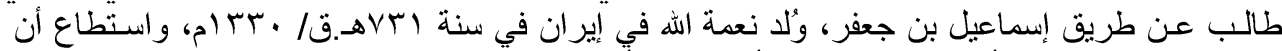

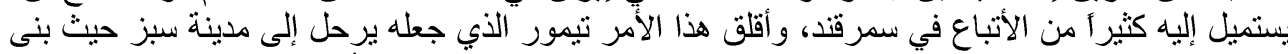

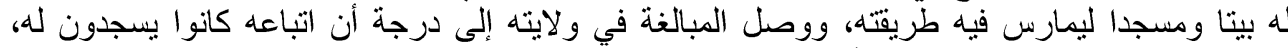

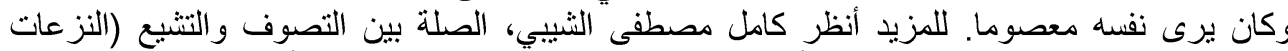

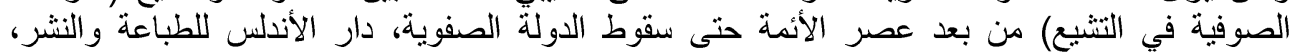

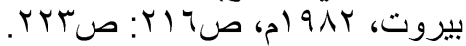

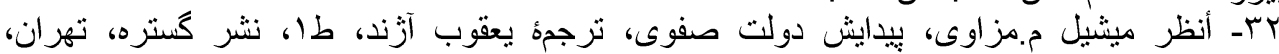

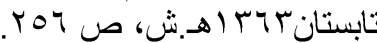

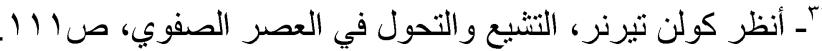

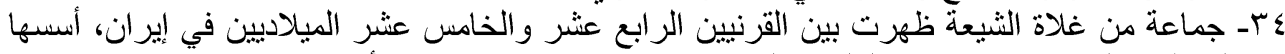

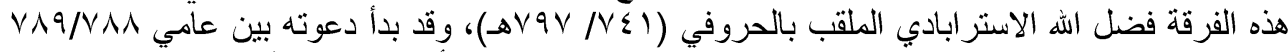

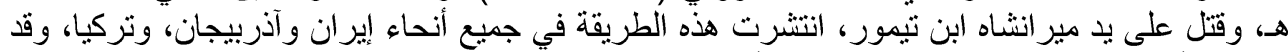

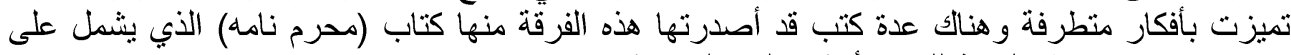

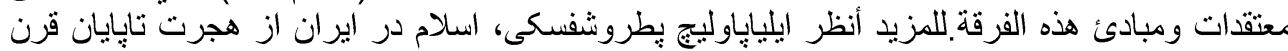

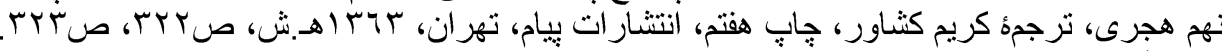

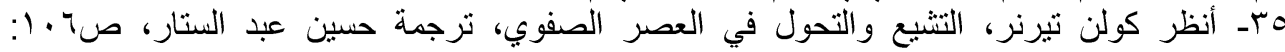

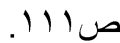

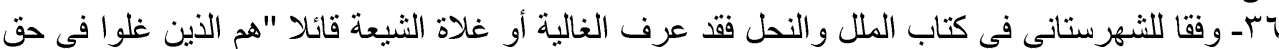

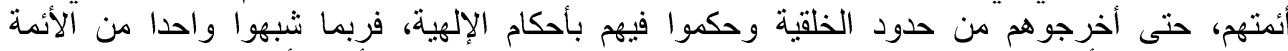

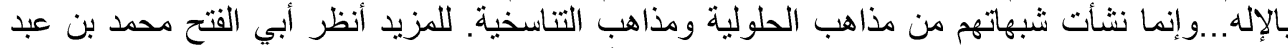

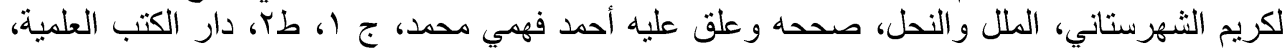

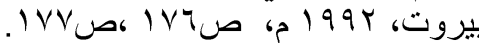

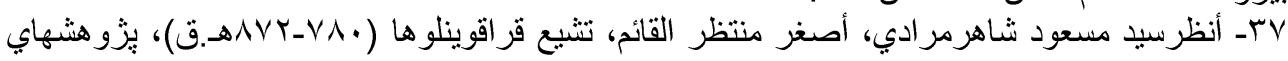

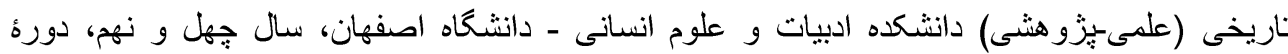

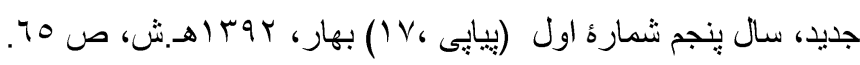

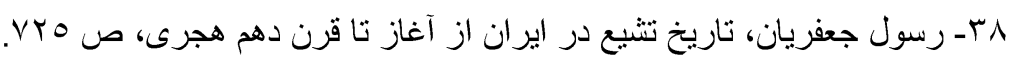

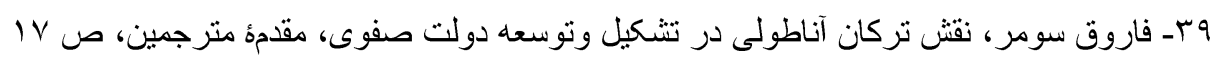

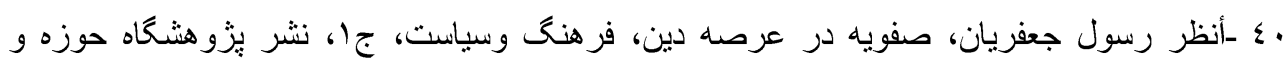




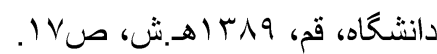

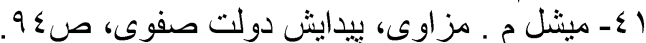

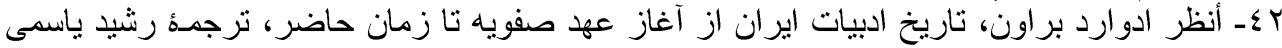

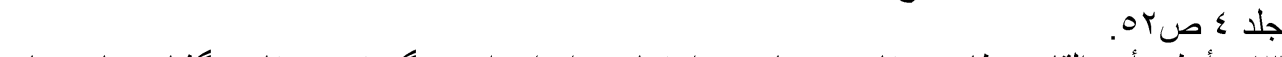

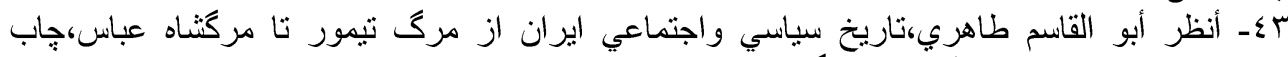

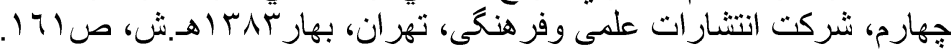

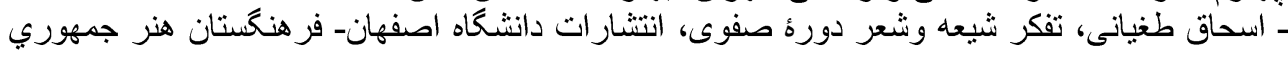

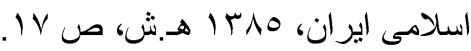

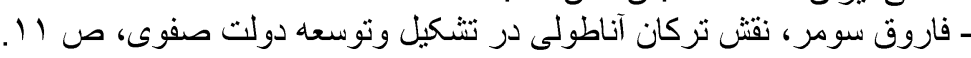

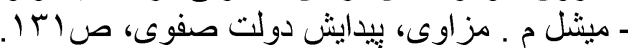

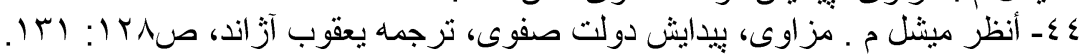

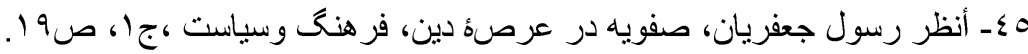

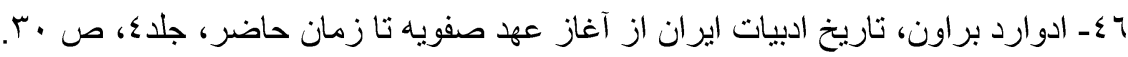

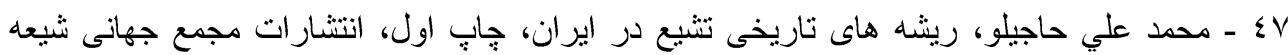

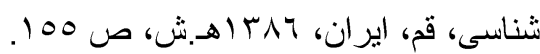

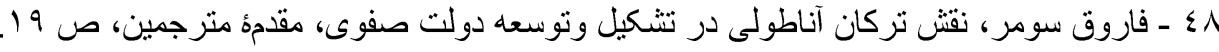

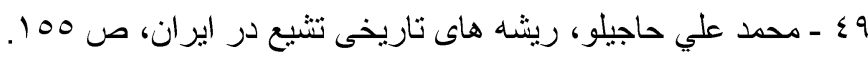

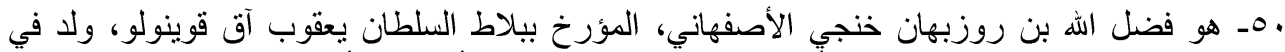

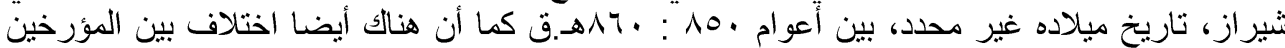

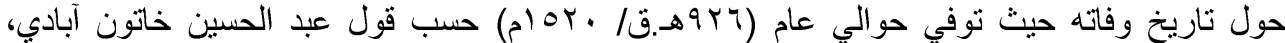

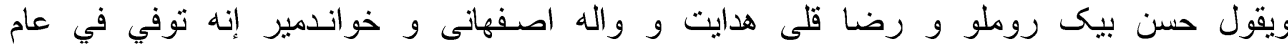

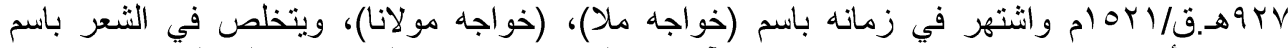

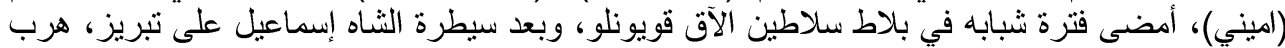

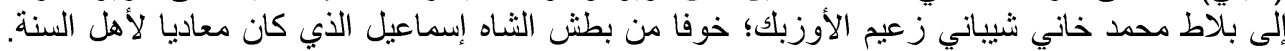

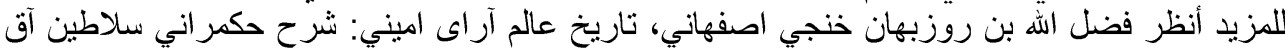

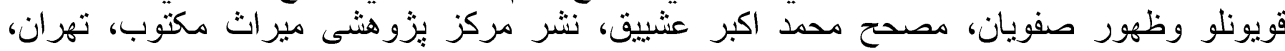

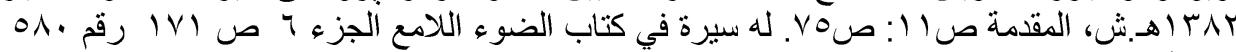

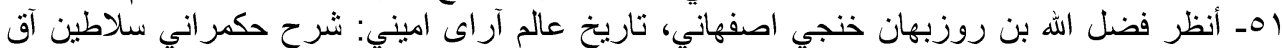

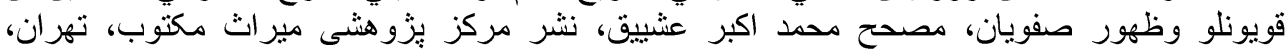

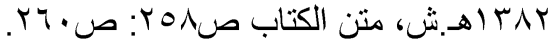

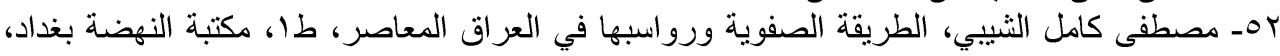
م

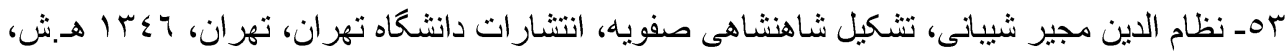

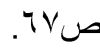

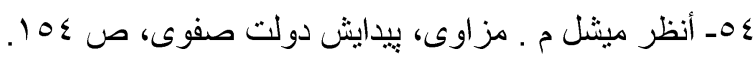

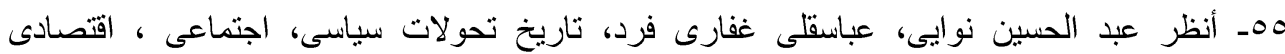

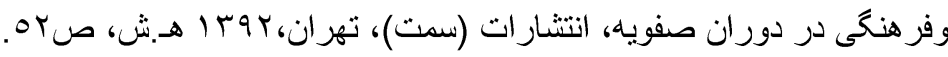

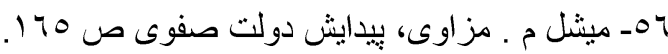

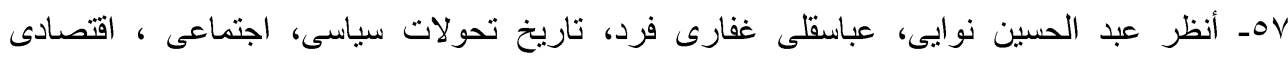

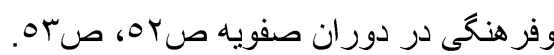

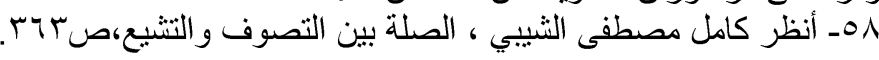

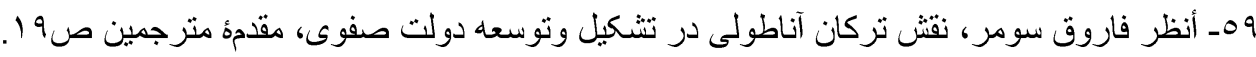




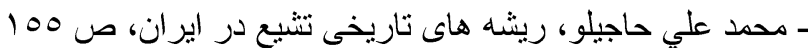

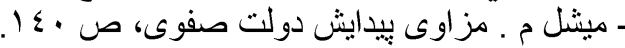

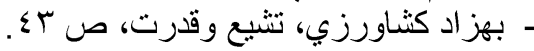

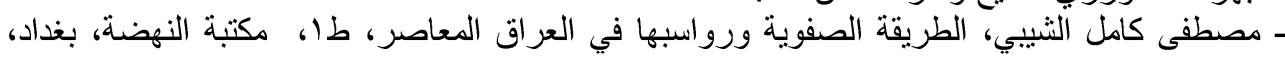

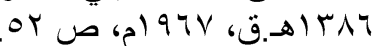

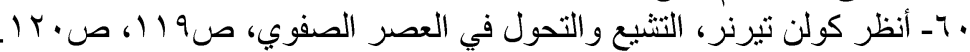

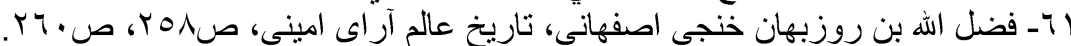

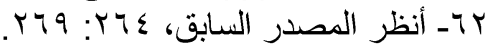

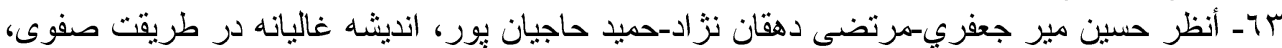

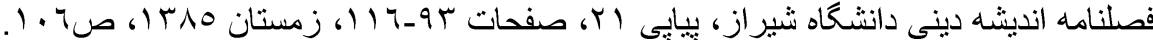

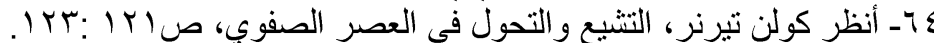

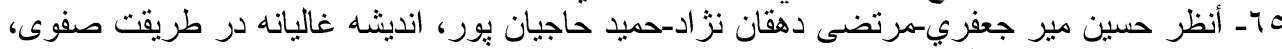

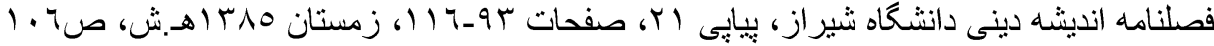

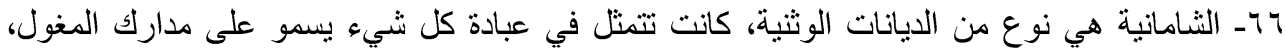

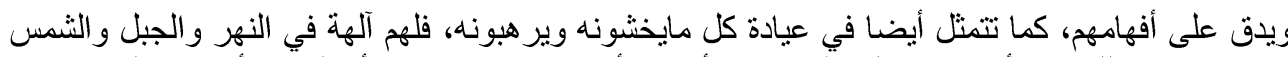

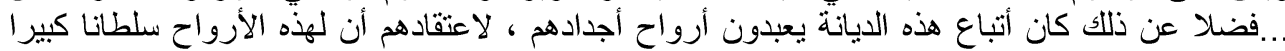

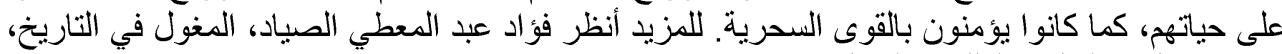

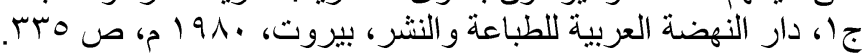

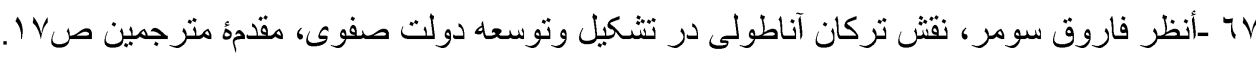

1 7- أنظر فاروق سومر، نقش تركان آناطولى در تشكيل وتوسعه دولت صفوى، صع (، ص 10.

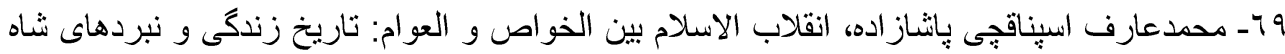

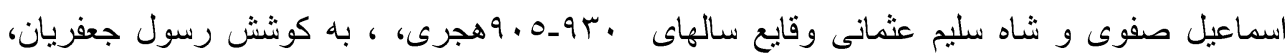

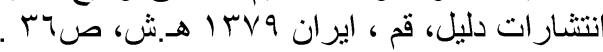

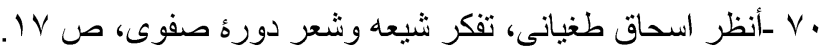

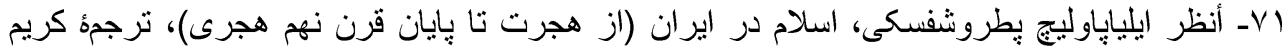

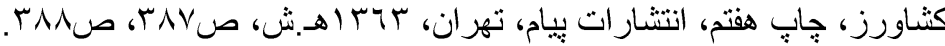

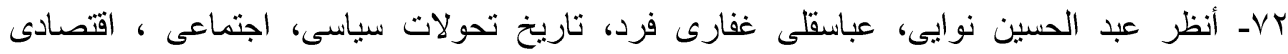

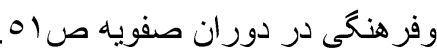

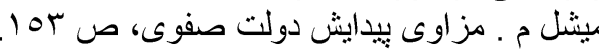

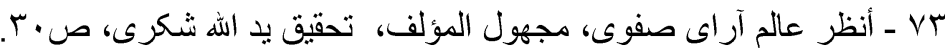

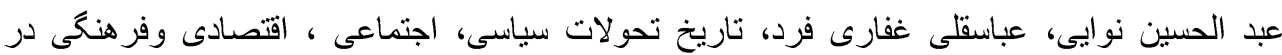
دوران صفويه صبن صوابنه

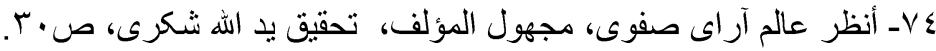

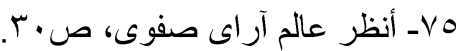

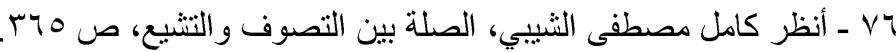

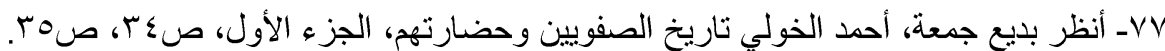

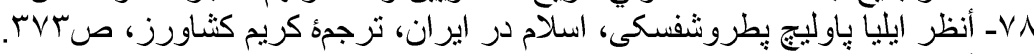

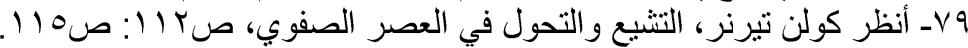

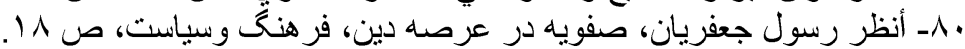

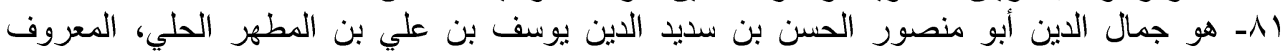

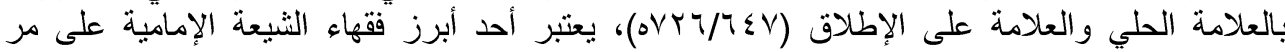


العصور، من مؤلفاته منتهى المطلب في تحقيق الدذهب، نظم البر اهين في أصول الدين، للمزيد أنظر محسن

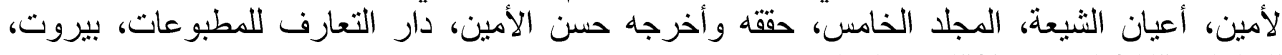

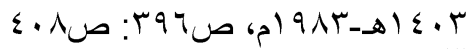

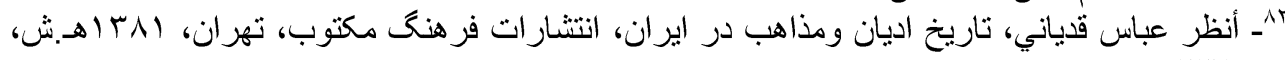

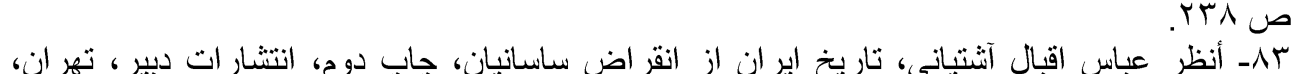

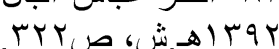

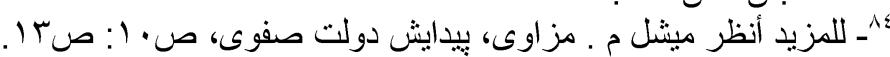

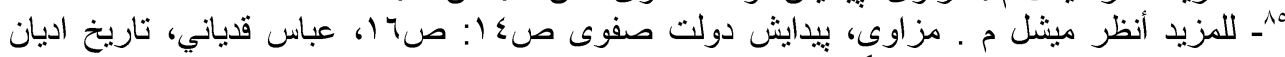

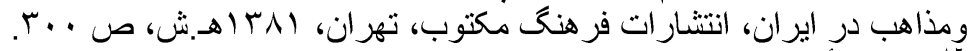

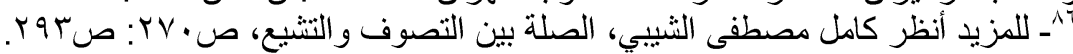

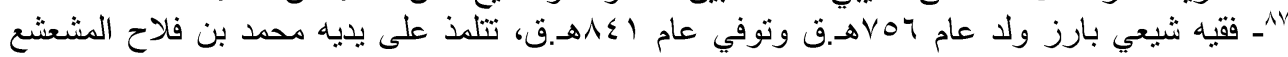

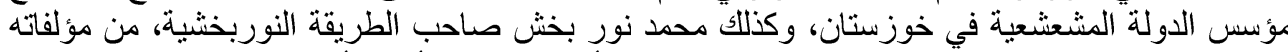
المهذب البارع في شرح المختصر النافع في الفقه، للمزيد أنظر محسن الأمين، أعبان الثنيعة، المجلد الثئن الثالث،

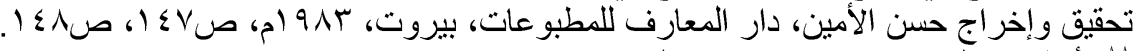

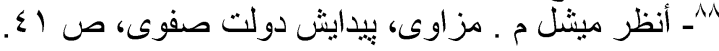

